\section{Contrast enhancement for ultrasound- guided interventions: when to use it and what to expect?}

\author{
Zeno Sparchez ${ }^{1,2}$, Tudor Mocan², Rares Craciun ${ }^{1,2}$, Mihaela Sparchez ${ }^{3}$, Christian Nolsøe ${ }^{4,5}$ \\ 13rd Medical Department, "Iuliu Hatieganu" University of Medicine and Pharmacy, Cluj- \\ Napoca; ${ }^{2}$ "Prof. Dr. O. Fodor" Regional Institute of Gastroenterology and Hepatology, Cluj- \\ Napoca; ${ }^{3}$ Department of Pediatrics, "Iuliu Hatieganu" University of Medicine and Pharmacy, \\ Cluj-Napoca, Romania; ${ }^{4}$ Center for Surgical Ultrasound, Department of Surgery, Zealand \\ University Hospital, Køge; ${ }^{5}$ Copenhagen Academy for Medical Education and Simulation \\ (CAMES), University of Copenhagen and the Capital Region of Denmark, Copenhagen E, \\ Denmark
}

The use of contrast-enhanced ultrasonography (CEUS) has recently become synonymous with high-standard ultrasonography (US). From expanding the reach of US diagnostics to improving the precision of various invasive procedures, CEUS is rapidly becoming a standard in numerous niches. However, proficiency in CEUS comes with a cost, both from a learning curve and material standpoint, and as every growing field, lacks firm evidence and standardization. Therefore, in the current paper, we aim to provide an evidence-based review of available methods and to discuss the advantages and pitfalls of CEUS in interventional procedures, trying to provide strong evidence whenever available, or at least an educated expert opinion if data are lacking.

Keywords: Contrast-enhanced ultrasonography; Interventional ultrasonography;

\section{Contrast enhancement}

Key points: Contrast-enhanced ultrasonography (CEUS) has long been a useful tool for refining ultrasonographic diagnosis. In recent years, CEUS has expanded its reach from diagnosis to interventional procedures, increasing their accuracy and therapeutic yield. The current review aims to better define the role of CEUS in interventional ultrasonography.

\section{Introduction}

Imaging guidance is a key factor in conferring both effectiveness and safety for numerous interventional procedures. Among the multitude of available imaging techniques, ultrasonography (US) and computed tomography (CT) are the most commonly used in guiding abdominal interventions [1-4]. However, US stands alone as the only true real-time method and remains the most preferred guiding tool, with several advantages over CT and magnetic resonance imaging (MRI), especially given its high accessibility. Yet, in comparison to sectional imaging, the lack of contrast administration

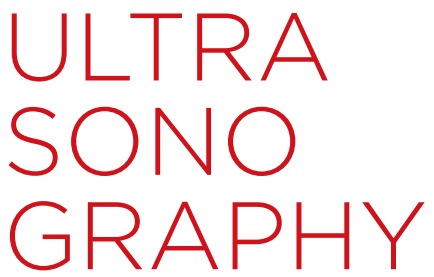

\section{REVIEW ARTICLE}

https://doi.org/10.14366/usg.21207 pISSN: 2288-5919 elSSN: 2288-5943 Ultrasonography 2022;41:263-278

Received: October 4, 2021

Revised: November 29, 2021

Accepted: December 9, 2021

Correspondence to:

Zeno Sparchez, MD, PhD, "Prof.

Dr. O. Fodor" Regional Institute of Gastroenterology and Hepatology, 1921 Croitorilor Street, Cluj-Napoca, Cluj County, Romania

Tel. +40-722890911

Fax. +40-264455995

E-mail: zsparchez@yahoo.co.uk

This is an Open Access article distributed under the terms of the Creative Commons Attribution NonCommercial License (http://creativecommons.org/ licenses/by-nc/4.0/) which permits unrestricted noncommercial use, distribution, and reproduction in any medium, provided the original work is properly cited.

Copyright (C) 2022 Korean Society of Ultrasound in Medicine (KSUM)

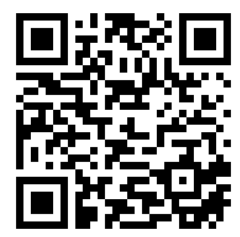

How to cite this article:

Sparchez Z, Mocan T, Craciun R, Sparchez $M$, Nolsøe C. Contrast enhancement for ultrasound-guided interventions: when to use it and what to expect?. Ultrasonography. 2022 Apr;41(2):263-278. 
previously limited the effectiveness of conventional US guidance. In clinical practice, there were numerous cases in which grayscale US did not suffice for guidance, an illustrative example being nonvisible, isoechoic lesions, which in the past required a referral for a contrast-enhanced CT-guided procedure $[5,6]$.

\section{US Contrast Agents and Harmonic Imaging}

The successful introduction of microbubble US contrast agents (UCAs) in the past decades has enabled the real-time contrastenhanced assessment of various tumors, parenchyma, or complex pathological structures $[7,8]$. Not only do microbubbles enhance the diagnostic capacities of US, but they also enable interventional procedures performed either for diagnostic (aspiration, punctures, biopsies) or therapeutic (drainages, ablations) purposes [5-10].

The mechanisms, particularities, and advantages of various UCAs are well documented and are not the focus of the current review $[5-7,11]$. However, the distinction between the two most frequently used contrast agents, SonoVue (Bracco, Switzerland) and Sonazoid (GE Healthcare, Amersham, UK), is of particular interest. SonoVue microbubbles are composed of sulfur hexafluoride gas with a phospholipid shell. The contrast agent is metabolized by the liver and further exhaled by the lungs, providing the typical arterial (20-30 seconds), portal (45-90 seconds), and late (>180 seconds, but less than 10 minutes) phases. In contrast, Sonazoid (currently approved only in Japan, Korea, and Scandinavia) consists of microspheres of perfluorobutane stabilized by a monomolecular membrane of hydrogenated egg phosphatidylserine, embedded in an amorphous sucrose structure. Unlike SonoVue, Sonazoid is taken up by Kupffer cells in the post-vascular phase, leading to an additional postvascular phase (Kupffer phase, 5 to 30 minutes after the injection), providing extremely stable images suitable for repeated scanning and interventions, and thus removing the time-constraint generated by rapid contrast clearance. Moreover, the Sonazoid bubbles have a relatively narrow size distribution, are very robust-allowing for high mechanical index (MI) scanning ( $\mathrm{Ml}=0.2-0.3)$ and are not deterred by the use of higher US frequencies $[5,12]$.

\section{Applications: Intravascular, Intracavitary, and Combined Use}

The UCA is manually administered through an intravenous line, most commonly via an antecubital vein, followed by a $10 \mathrm{~mL}$ flush of $0.9 \%$ normal saline. To avoid disrupting the microbubbles, UCAs should be administered relatively slowly. A contrast-enhanced ultrasonography (CEUS)-compatible US system with contrast agentspecific software that uses conventional low-MI imaging is required.
Contrast enhancement can be shown on a split-screen display with a conventional B-mode image and a low-MI CEUS image presented either side-by-side, or on a single-screen display where the CEUS image is presented as a color overlay on the conventional B-mode image $[5,6,9,11,13]$.

The technique for intracavitary administration of UCAs is similar to the technique used for focal lesions. The key differences consist of the UCA dosage and injection modality. According to the most recent European Federation of Societies for Ultrasound in Medicine and Biology (EFSUMB) Guidelines published in 2020, the dose range recommended for extravascular (intracavitary) CEUS is $0.1-1 \mathrm{~mL}$ SonoVue diluted in $10 \mathrm{~mL}$ of $0.9 \%$ saline [7]. The dose of UCA depends on the type of cavity (physiological or nonphysiological cavity) and the aim of the study. To emphasize (or exclude) a connection between two cavities, the anatomy of fistulas, or pleuro-peritoneal communication, a higher dose $(1-2 \mathrm{~mL})$ is necessary. Conversely, to delineate the cavity of a collection (abscess, pseudocyst), only a few drops of UCA suffice to avoid artifact formation. The route of administration is either through a previously placed drainage tube or through a needle (18 G, Chiba), which is inserted into the cavity or excretory systems (biliary or renal) $[5,9,11,13-15]$. To address specific clinical questions (e.g., liver abscess), a combination of these two modalities, in any order, can be used. When performing similar examinations successively, it is necessary to disrupt the microbubbles by deploying a higher-energy US pulse compared to normal B-mode levels before repeating the UCA administration $[9,11,15]$. Other than local pain during the injection, no other adverse reactions have been documented in multiple clinical studies [11].

\section{Benefits of CEUS Guidance}

CEUS has the capacity of emphasizing the macrovasculature and, above all, the microvasculature of the parenchyma and tumors. Besides the well-accepted use in the detection and characterization of various tumors, the use of this technique has enabled the delimitation of areas with abnormal or absent vasculature $[5,9,11,13]$. These unique features are valid for both focal parenchymal lesions (e.g., tumors, abscesses) and post-procedural scars (e.g., post-ablation necrosis, embolization). The potential benefits of CEUS guidance are presented in Table 1 .

The intracavitary administration allows the morphological assessment of various cavities, potential communications with adjacent structures or organs, and the evaluation of procedural success $[5-7,9,11,14,15]$. 


\section{Technique of Intravascular CEUS-Guided Interventions: Preprocedural versus Real-Time}

The timing of the UCA injection can add a nuance of precision to CEUS-guided interventions. In most cases, preprocedural CEUS is enough to increase the spectrum of relevant information about the point of interest (morphology, necrotic areas). It facilitates a more accurate procedure plan, which will subsequently be performed in grayscale mode. Furthermore, by utilizing GPS navigation, the operator can mark the desired target during the enhancement

Table 1. The potential benefits of CEUS guidance

\begin{tabular}{llll}
\hline \multicolumn{1}{c}{ Benefits } & \multicolumn{1}{c}{ Means } & \multicolumn{1}{c}{ Targets } & \multicolumn{1}{c}{ Interventions } \\
\hline $\begin{array}{l}\text { Delineation of areas with different } \\
\text { microvascularization }\end{array}$ & $\begin{array}{l}\text { Detection of invisible/poorly visible } \\
\text { tumors in B-mode ultrasonography }\end{array}$ & $\begin{array}{l}\text { Small lesionslsoechoic lesions (hepatocellular } \\
\text { carcinoma, liver metastases) } \\
\text { Lung tumors in atelectatic parenchyma }\end{array}$ & $\begin{array}{l}\text { Biopsy } \\
\text { Ablations }\end{array}$ \\
Detection of unperfused areas & $\begin{array}{l}\text { Detection of necrosis in inflammatory } \\
\text { lesions }\end{array}$ & $\begin{array}{l}\text { Abscesses (liver, kidney, lung) } \\
\text { Complex solid-liquid inflammatory lesions }\end{array}$ & $\begin{array}{c}\text { Aspiration } \\
\text { Drainage } \\
\text { Post-therapeutic evaluation }\end{array}$ \\
& $\begin{array}{l}\text { Detection and assessment of necrosis } \\
\text { after ablation }\end{array}$ & $\begin{array}{l}\text { Liver tumors } \\
\text { Kidney tumors }\end{array}$ & Re-ablation of viable \\
Increasing the yield of biopsies & Detection of necrosis in tumors & Liver, kidney, retroperitoneal, lung & Biopsy of perfused areas \\
\hline
\end{tabular}

CEUS, contrast-enhanced ultrasonography.

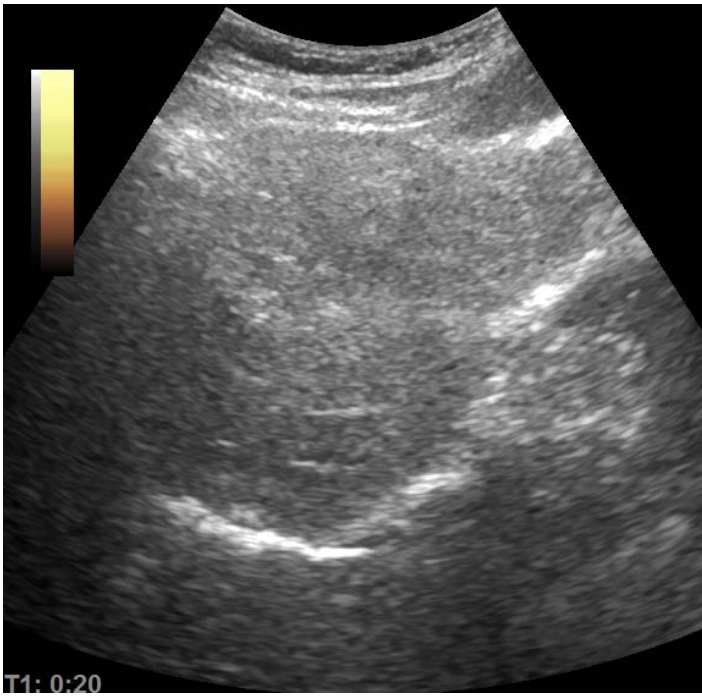

A

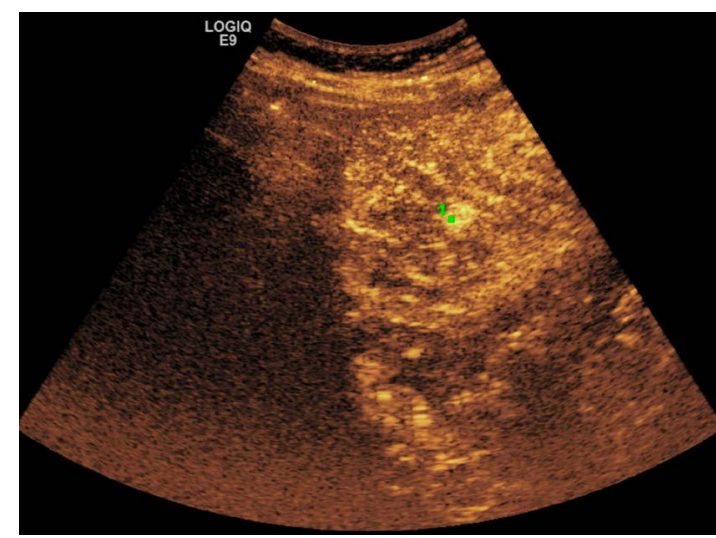

C

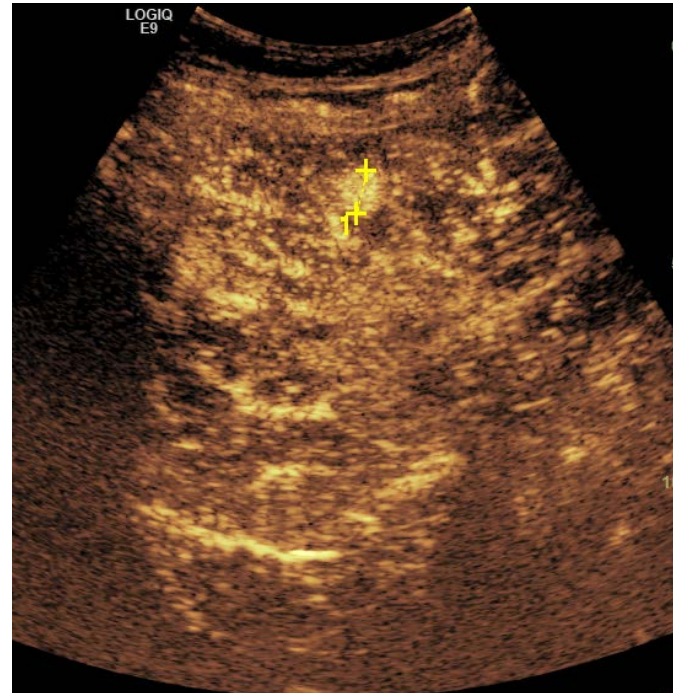

B

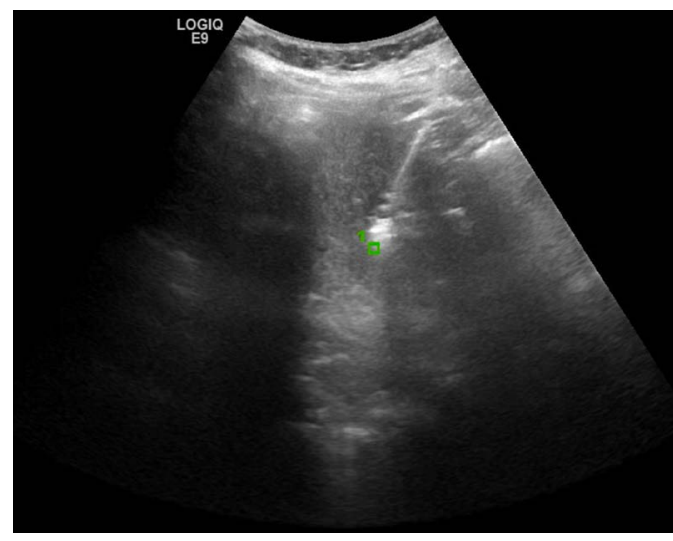

D
Fig. 1. Hepatocellular carcinoma.

A. Grayscale ultrasonography could not detect a small recurrent hepatocellular carcinoma nodule (11 mm), previously depicted on a computed tomography scan. B, C. During contrast-enhanced ultrasonography, the hyperenhancing nodule became apparent ( $B$, marked in yellow), and allowed GPS marking (C, green dot). D. Subsequently, microwave ablation was performed in grayscale mode, targeting the previously marked area. 
phase and expand the benefits of preprocedural CEUS to real-time guidance (Fig. 1) $[13,16]$.

However, real-time CEUS is the most precise manner of guidance, although it requires a more advanced skillset. It was also the first technique utilized at the time of the use of the first-generation UCA Levovist [17]. There are numerous sequences in which the UCA injection can be synchronized with the puncture, depending on the type of procedure. Typically, in the case of SonoVue, the 4.8 $\mathrm{mL}$ vial is subdivided into up to four doses. The first dose is used for pre-planning and mapping, while the subsequent doses are used for real-time guidance. In between the first and second doses, preparations can be performed (sterilization, drape placement, and local anesthesia). Real-time guidance is most frequently required in two clinical scenarios: to avoid large areas of tumoral necrosis (Fig. 2) and to locate obscure B-mode lesions. Consequently, for liver tumors, the moment of needle insertion should be synchronized with the desired outcome: arterial phase (10-30 seconds after the UCA injection) to avoid undesired areas of puncture or to target

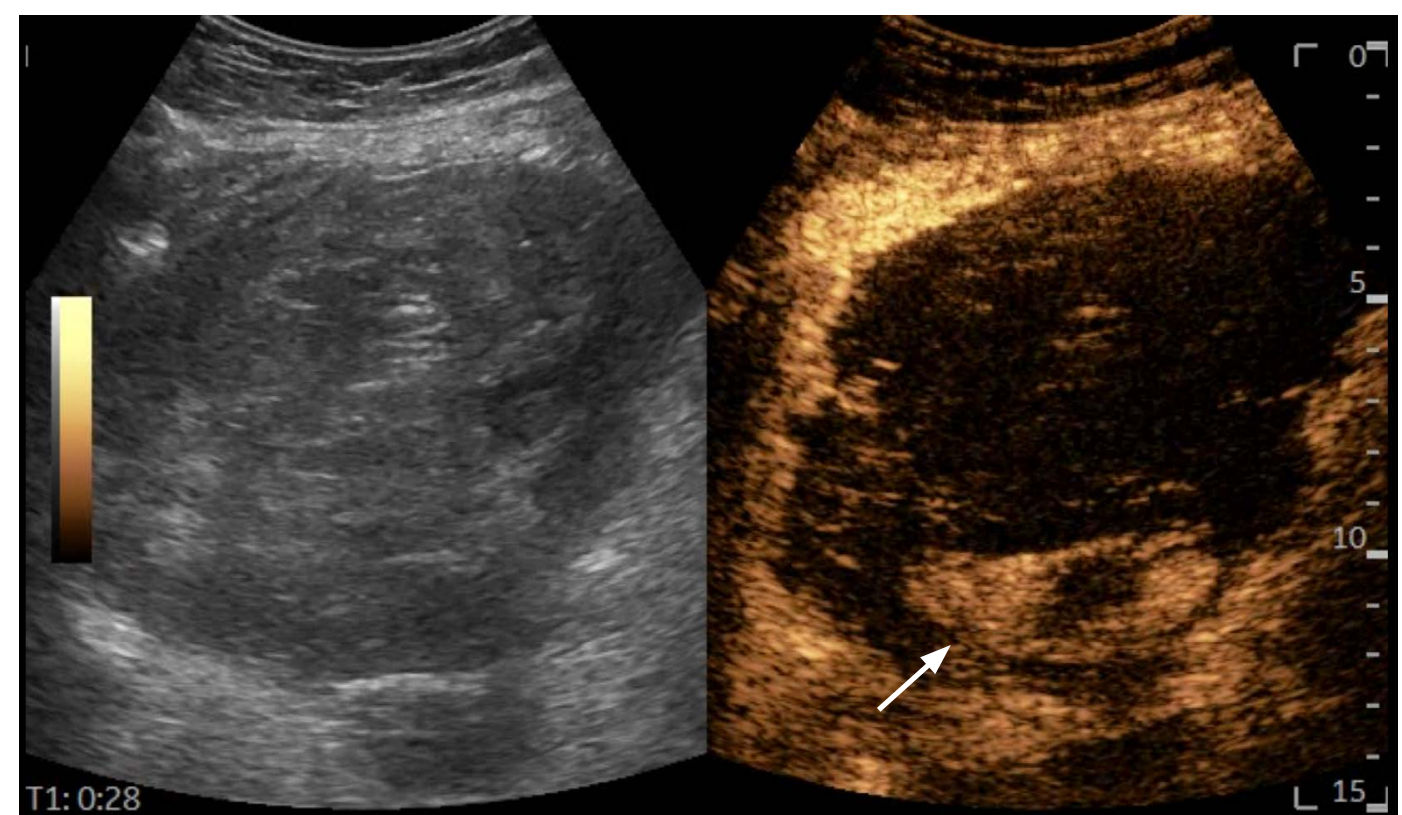

A

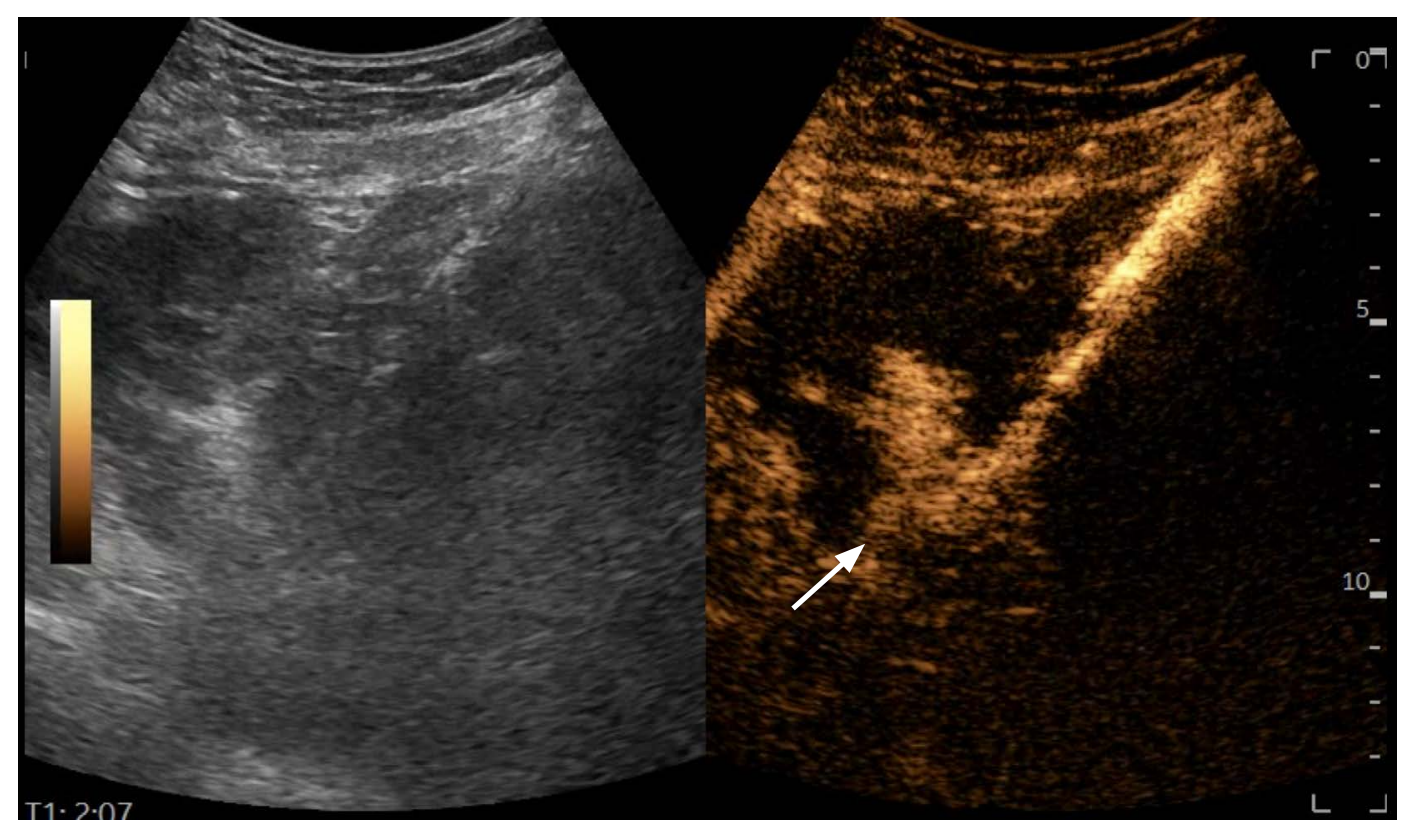

Fig. 2. A large tumoral mass, exceeding $10 \mathrm{~cm}$ in diameter, visualized in grayscale mode.

However, during contrastenhanced ultrasonography (A), only a small hyperenhancing area is visible (arrows). Targeting the hyperenhancing area (B) significantly increases the biopsy yield, minimizing the risk of uninterpretable pathology reports. 
hypervascular lesions not seen in B-mode US and the portal (30120 seconds) and parenchymal (120-600 seconds) phases for targeting metastasis that is inconspicuous in grayscale images (Fig. 3) $[5,9,13,18,19]$.

The use of real-time CEUS can sometimes become a significant challenge. When the biopsy is performed in the late phase, which can last up to 7 minutes, time allows for multiple passages. On the contrary, guidance in the 30-second arterial phase can become a race against the clock, allowing no room for error. This limitation can be overcome by using needle guides and attentive planning during the mapping CEUS $[15,20,21]$. There might be concerns about needle visibility during CEUS. Yet, in most cases, this does not represent a real issue, and the use of a split-screen view resolves needle visualization.

Upon advancing through the learning curve, each user can make slight variations of the working algorithm, to better suit personal preferences.

\section{CEUS-CT/MRI/Positron Emission Tomography-CT Fusion}

Conventional B-mode US may overlook some lesions, especially if

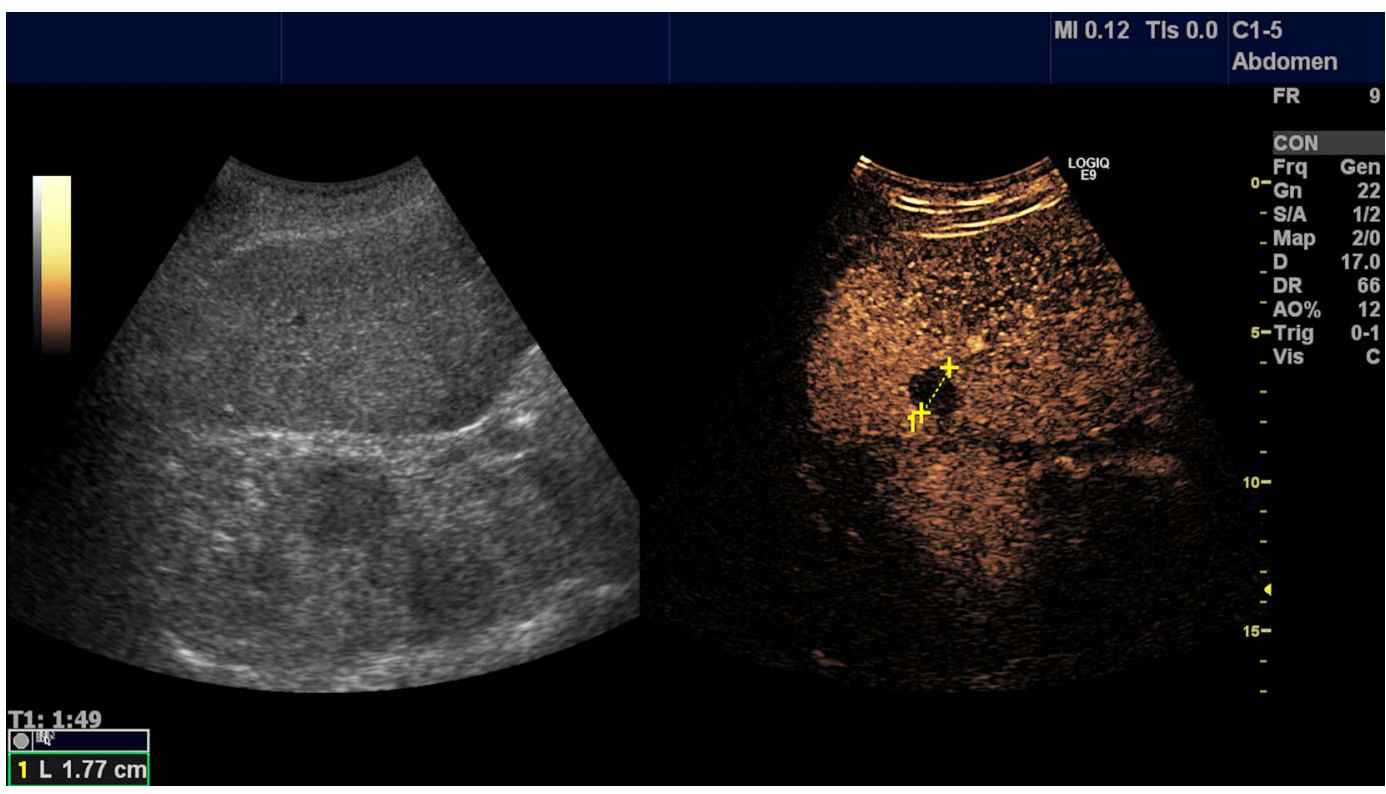

A

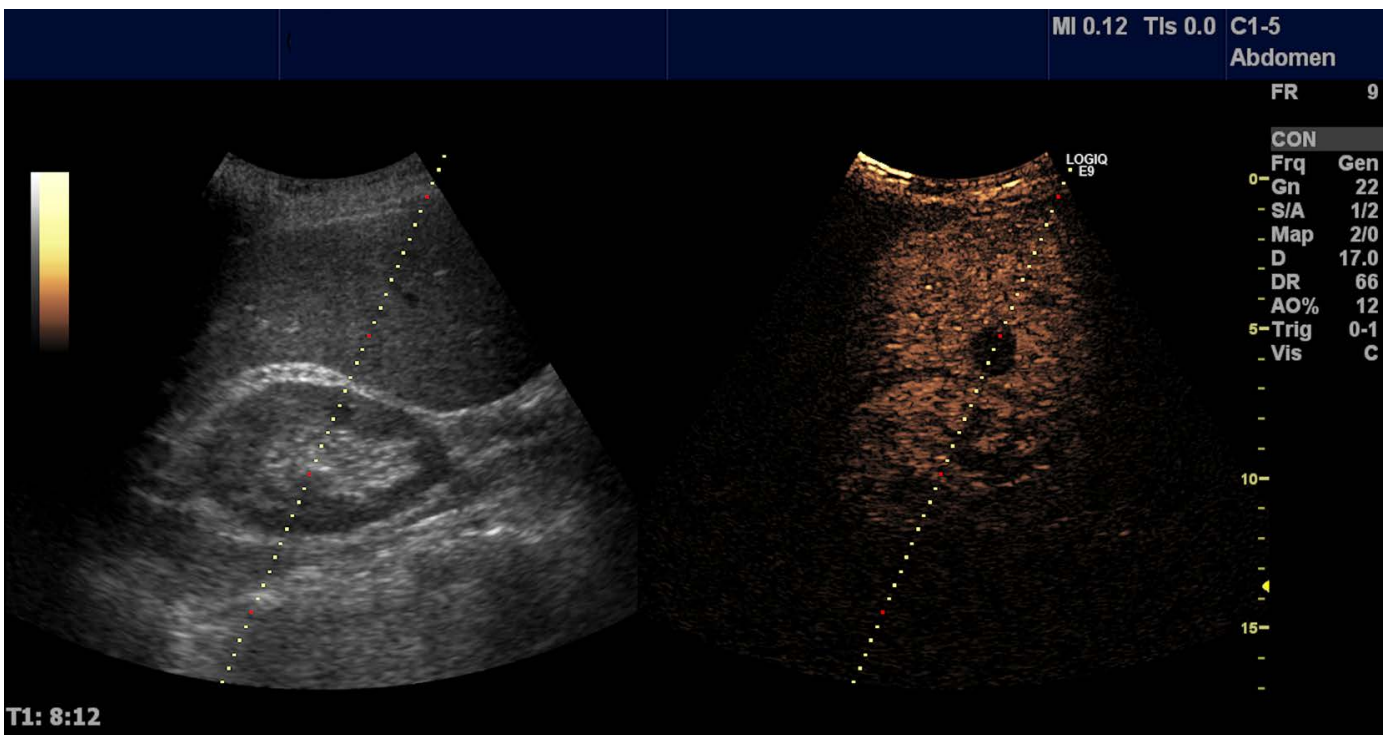

B
Fig. 3. Female patient with a previous history of breast cancer.

Referred for ultrasoundguided biopsy of suspected liver metastasis seen on computed tomography. On conventional B-mode imaging, no lesion could be found; however, contrastenhanced ultrasonography (CEUS) clearly demonstrates a suspicious wash-out lesion $(A)$ in the right liver lobe and a CEUS-guided biopsy (B) shows metastasis from breast cancer. 
they are isoechoic or small. Fusion imaging increases the detection rate and is of great help in guiding percutaneous interventions (biopsies, ablations) on the liver. However, the sensitivity of fusion imaging is not always perfect, with some small nodules still remaining undetected [22]. When fusion imaging is insufficient, adding CEUS in the US-CT fusion guidance increases the conspicuity of some lesions, which might prove useful, especially in small nodules (Figs. 4, 5) [23].

The introduction of CEUS guidance and other complementary methods has changed how we think and plan interventional procedures. With recent technical developments, new algorithms will most likely emerge. Is there also a paradigm shift in interventional ultrasound after the introduction of these methods? The following paragraphs will address this question.

\section{CEUS as a Tool to Increase the Efficacy of Percutaneous Biopsy}

Despite dramatic improvements in imaging- and biomarkerbased diagnosis in recent years, percutaneous biopsy still plays a

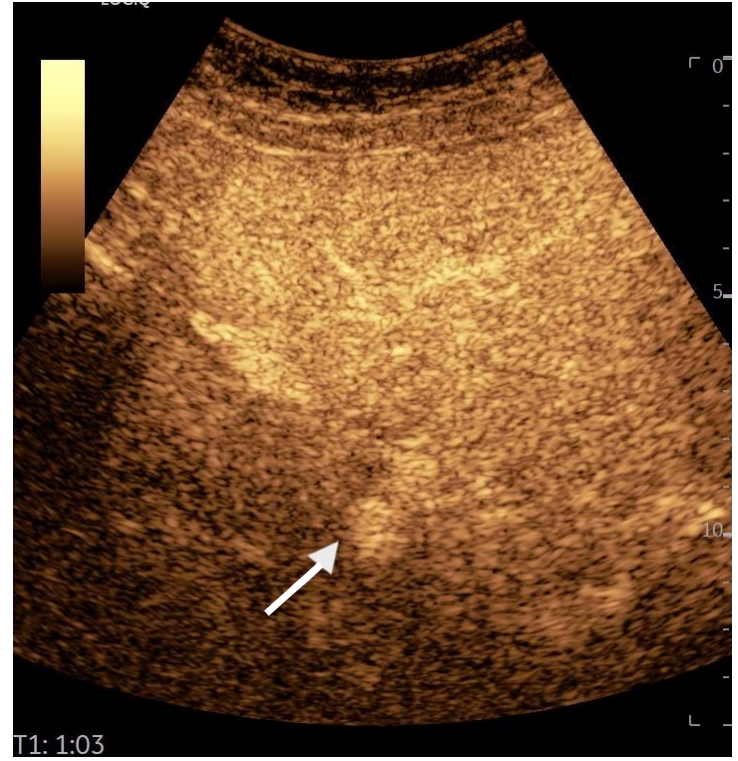

A

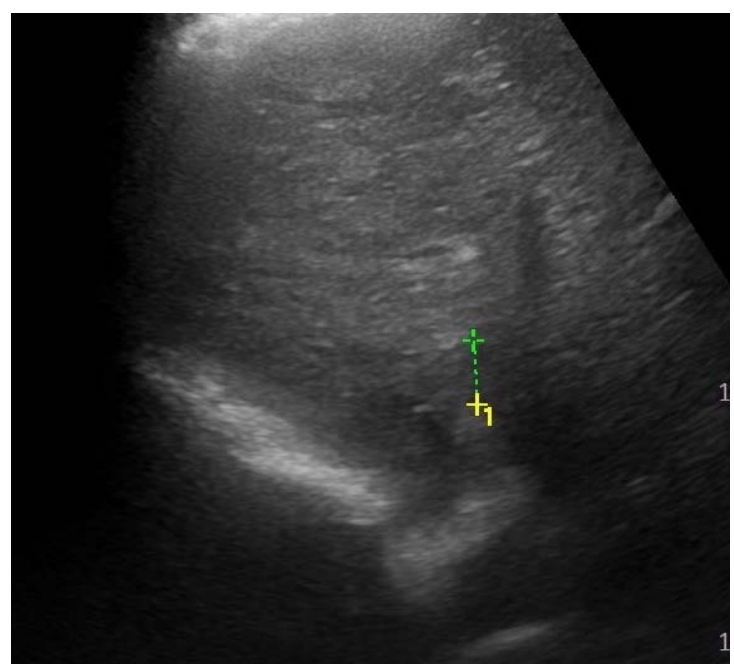

C

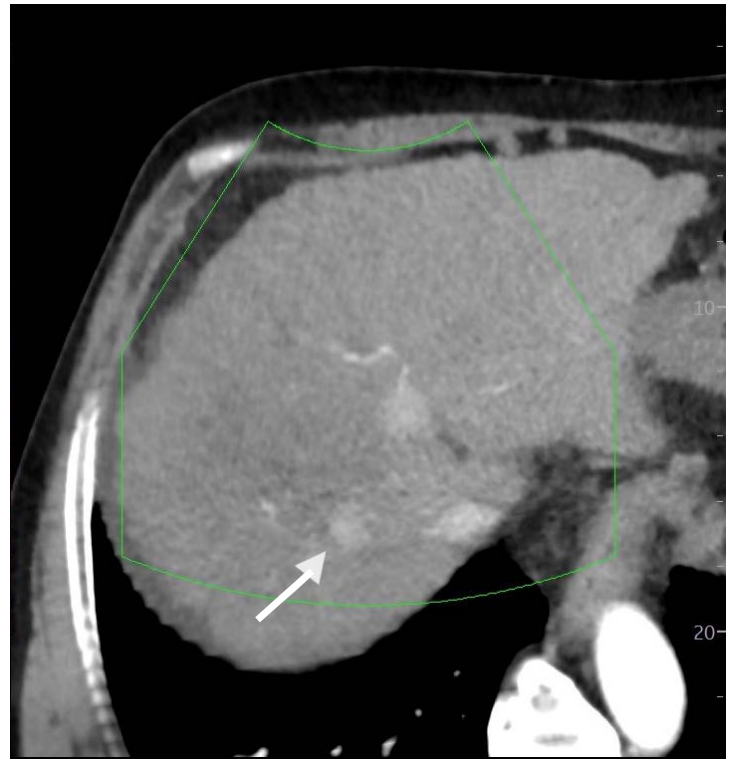

B

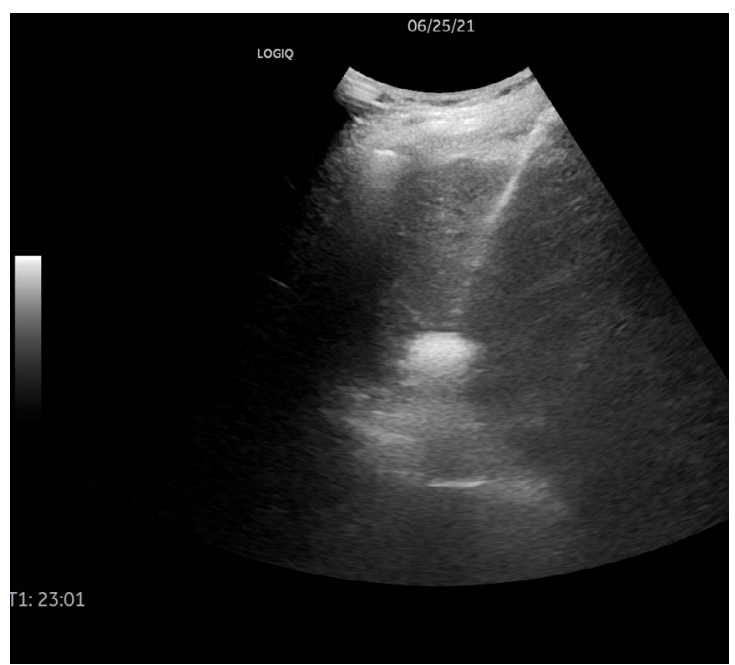

D

Fig. 4. Multicentric hepatocellular carcinoma.

In the case of a patient with multiple hepatocellular carcinoma nodules and a prior ablation session, a small nodule (arrows) was located on contrast-enhanced ultrasonography (CEUS) and computed tomography (CT) scans (A, B), while being completely inapparent in grayscale mode (C). CEUS-CT fusion enabled a successful session of microwave ablation (D). 
pivotal role in providing the most accurate diagnosis. With all the advantages offered by US guidance, the overall sensitivity of this method in the diagnosis of tumors remains around $90 \%$ [13].

The potentially added value of CEUS in tumoral diagnosis through percutaneous biopsy may be related to several factors.

\section{Improving Lesion Targeting}

Using CEUS, the conspicuity of focal lesions (liver, kidney, and pancreas) is improved. This is true for both small, isoechoic lesions and large, isoechoic infiltrating tumors. CEUS guidance might be used in the arterial phase for hypervascular lesions not seen in grayscale US, such as small hepatocellular carcinomas (HCCs) in patients with cirrhosis, or the late phase for liver metastases [13]. With the use of the new UCAs like Sonazoid, it became possible to target the liver lesions in the Kupffer phase (20-30 minutes after contrast injection), practically eliminating the time-constraint to perform the biopsy [12]. The use of CEUS before a biopsy may identify new lesions with an easier pathway for biopsy. The added value of CEUS is probably of most relevance when lesions are embedded in an already modified parenchyma and are otherwise difficult to detect (HCC nodules in liver cirrhosis, lung cancer in atelectatic parenchyma, or abscesses in pneumonia) [24-26]. Not least, CEUS is also relevant for patchy tumoral organ involvement, such as lymph nodes or prostatic adenocarcinoma [13].

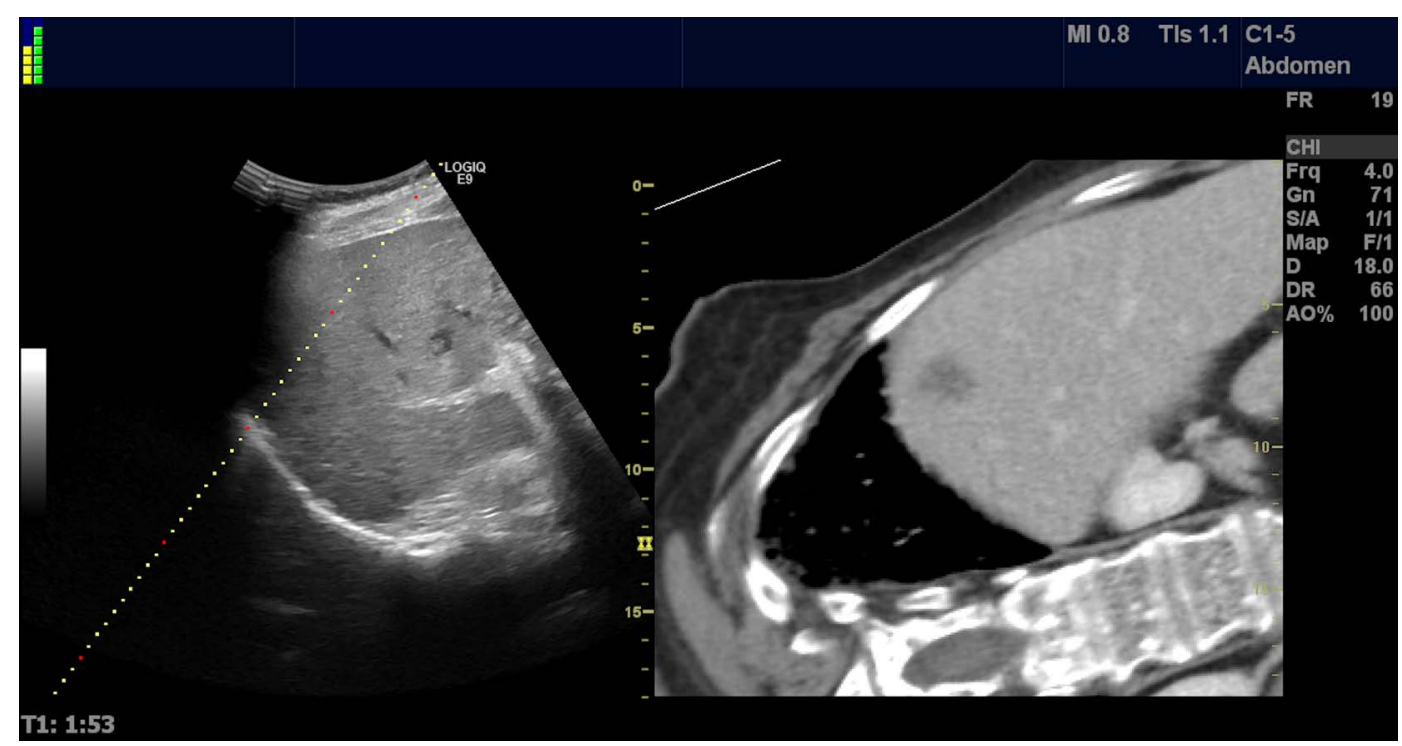

A

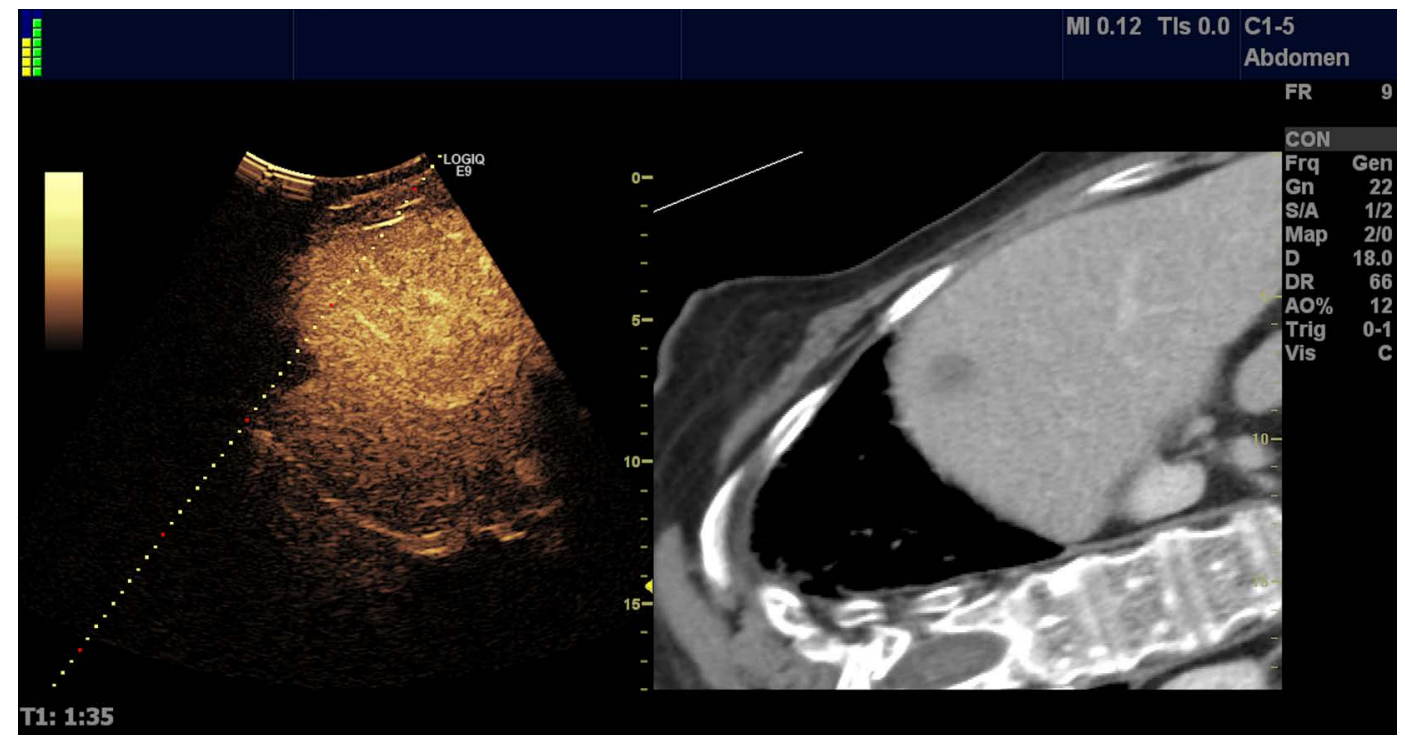

B
Fig. 5. Female patient with a previous history of both breast cancer and colorectal cancer.

Computed tomography (CT) shows metastasis cranially in the right liver lobe. B-mode fusion with $\mathrm{CT}$ demonstrates the lesion poorly due to the high position and interposed lung tissue (A). Repeating the procedure under contrast-enhanced ultrasonographic guidance (B) made the lesion much more conspicuous and the biopsy could be safely carried out. Microscopy reveals metastasis from colon cancer. 


\section{Avoiding Avascular Areas}

Avoiding avascular areas in larger tumors (retroperitoneal, renal, and adrenal) by directing the needle towards the vascular, viable areas (Fig. 2) $[5,6,13]$. The biopsy of small viable tumoral areas in a necrotic lesion requires the use of real-time contrast guidance for precise targeting.

\section{Abstaining from Biopsy When It Is Unnecessary}

Although sectional imaging methods have a good sensitivity for diagnosing focal liver lesions, there are some circumstances (i.e., small lesions, especially hemangiomas) where the lesions may be misinterpreted or have a nonspecific pattern. In those cases, CEUS performed before the biopsy may change the diagnosis and thus avoid the biopsy $[6,13,27,28]$.

The improved accuracy of CEUS-guided liver and thoracic biopsies versus conventional B-mode guidance has been reported in numerous papers $[16,19,26,27,29]$. Intending to avoid necrosis, CEUS-guided biopsy increases the diagnostic yield of the pathology report by up to $20 \%$ in liver biopsies [6]. Furthermore, the CEUSguided puncture of poorly visible or invisible liver lesions has a success rate of $86 \%$ to $100 \%[6,19,30]$. In advanced chronic liver disease, CEUS adds a $20 \%$ increase to the overall sensitivity and a 30\% sensitivity increase for lesions with poor conspicuity on B-mode US [26]. Moreover, using Sonazoid, it was reported that CEUS guidance significantly increased the technical success rate by $26 \%$ and the rate of successful single puncture attempts by $20 \%$ compared to B-mode guidance [31].

Adding CEUS to US-CT fusion guidance increases the visibility of lesions, with $77.8 \%-93.8 \%$ of initially invisible lesions being detected [32,33].

In the biopsy of thoracic lesions, in comparison to grayscale US guidance, CEUS guidance increases the sensitivity of the procedure from $80.3 \%$ to $96.3 \%$, while decreasing the complication rate $(3.7 \%$ vs. $18.2 \%)$. This advantage was achieved by a better distinction between tumor and atelectasis and higher performance in detecting necrotic tissue [29].

Renal and other retroperitoneal tumors may grow very large, with frequent and extensive necrosis, rendering them suitable for CEUS guidance [13]. Preliminary reports have demonstrated the good feasibility of CEUS-guided biopsies, with diagnostic sensitivities of $96 \%$ in renal tumors and large retroperitoneal and intraperitoneal tumors (18\% higher than US-guided biopsies) $[34,35]$.

\section{CEUS-Guided Biopsy in Clinical Practice}

Although CEUS-guided percutaneous biopsy was shown to add $10 \%$ to $15 \%$ to the procedural success rate, its use in daily clinical practice is currently limited. A multicentric Italian study showed that real-time CEUS guidance was used in only $2.6 \%$ of 3818 biopsies. In order of frequency, CEUS-guided biopsy was used to avoid necrosis $(39.8 \%$ of cases), to improve the target visibility (33\%), and to target invisible lesions (27\%). Approximately one-fourth (25.2\%) of cases had a previously non-diagnostic biopsy. There are several reasons for the limited use of CEUS-guided biopsy in clinical practice, as follows: good experience for operators performing USguided biopsy even for difficult cases; the routine use of CEUS in the diagnostic workup with valuable information already available at the time of biopsy; and the technical difficulty of real-time guidance, which is challenging for deep and small lesions [36].

In conclusion, while CEUS guidance is not required for every case of focal lesion biopsy, there are many clear-cut scenarios in which enhancing the lesion enhances the overall results. Although routine use may increase costs and procedure time without adding significant value [21], a judicious approach can maximize the outcome.

\section{CEUS in Percutaneous Drainage Procedures: Abscesses, Biliary Tree, and Nephrostomy}

Percutaneous drainage procedures are probably the latest realm conquered by CEUS guidance, adding refinement to what was previously a supplement to B-mode. However, since the field is still emerging, the present data remain scarce and unorganized, mostly consisting of case reports and small series.

\section{Abscess Drainage}

Abscesses can take numerous shapes and sizes. Thus, their correct management can become a significant challenge especially with regards to exactly when and where to place the tube to achieve the best results. The best timing can be selected using serial evaluations to refrain from premature or unnecessary procedures (without the toll of multiple CT scans) as proven by recent data [37] and illustrated in Fig. 6. The grayscale appearance might often be misleading, as septa, multilocularity, or fistulas can detract from therapeutic success [6]. In this situation, intracavitary CEUS can help, as it provided additional information regarding undrained areas or communication with anatomical structures (Figs. 7,8 ) in almost $50 \%$ of the cases in the largest available series on the topic [38].

\section{Biliary Tree: Cholangiography and Drainage}

There is a purported role of CEUS in characterizing the biliary tree, being a bedside, non-irradiating alternative to fluoroscopy. Once the biliary tree is percutaneously accessed, the injection of a small, diluted amount of UCA can confirm the needle location, define 


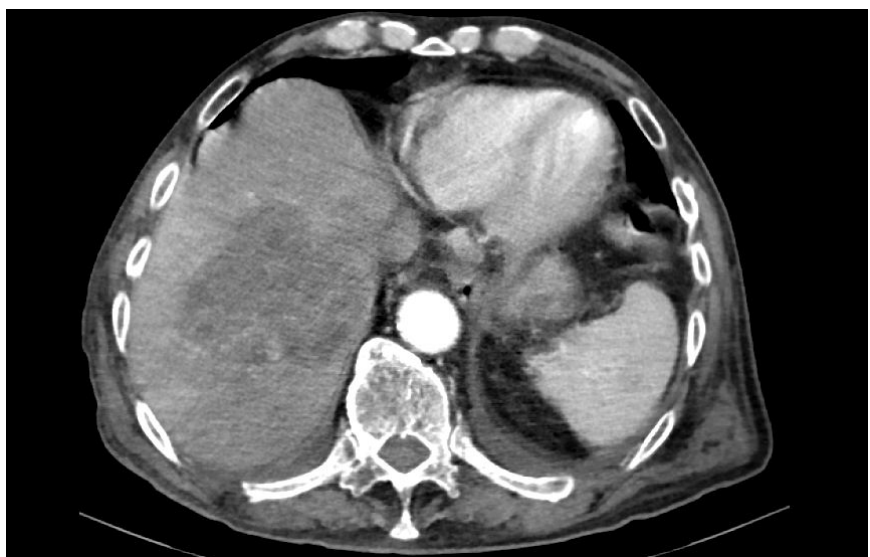

A
Fig. 6. Klebsiella pneumoniae liver abscess.

A. Computed tomography scan depicts a nonspecific tumoral mass, with uncharacteristic enhancement. B. Ultrasonographic and contrast-enhanced ultrasonographic appearance of a large Klebsiella pneumoniae liver abscess, with multiple interior septa that would have rendered any drainage attempt unsuccessful.

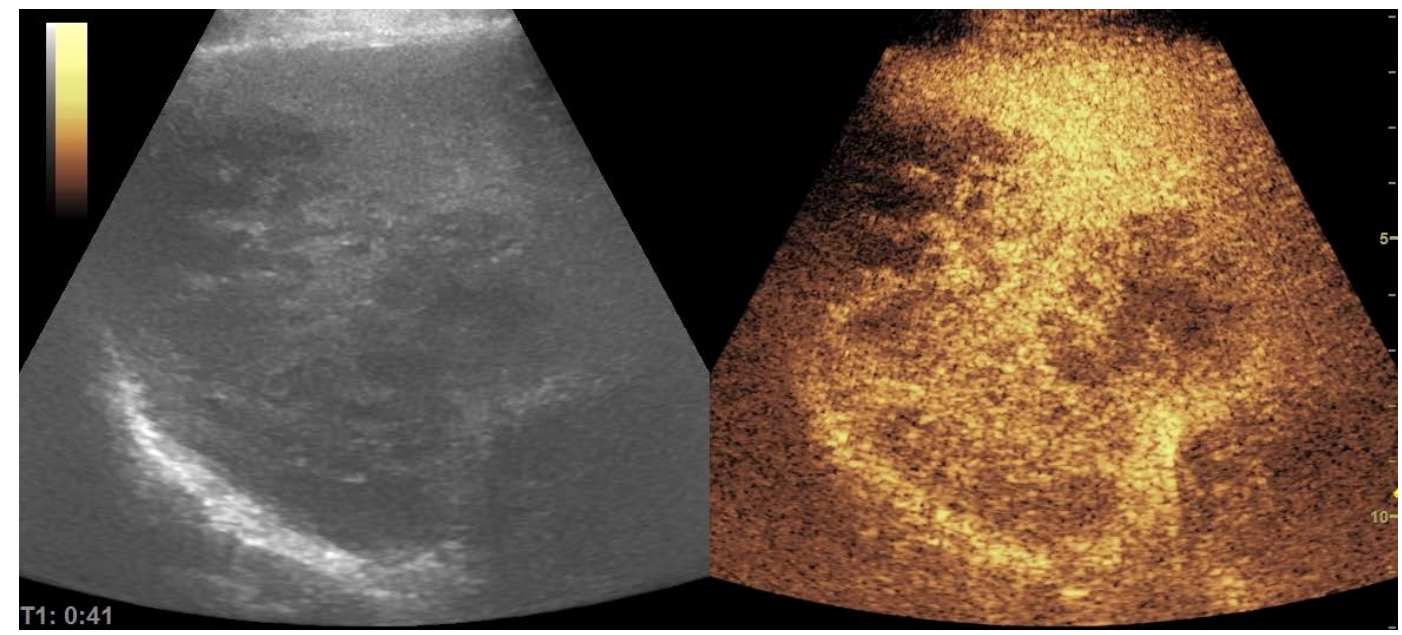

B

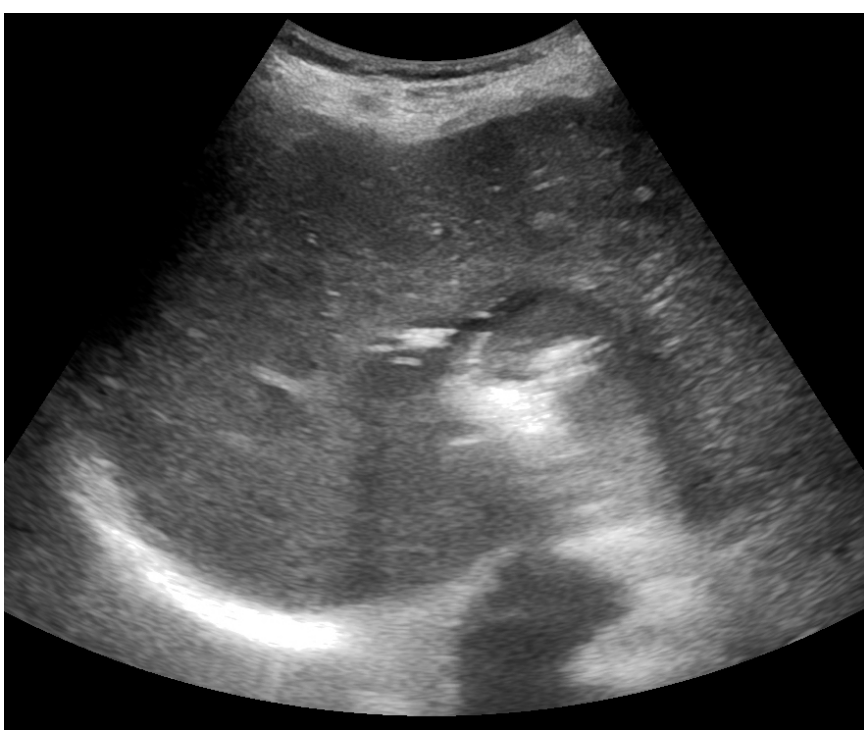

A

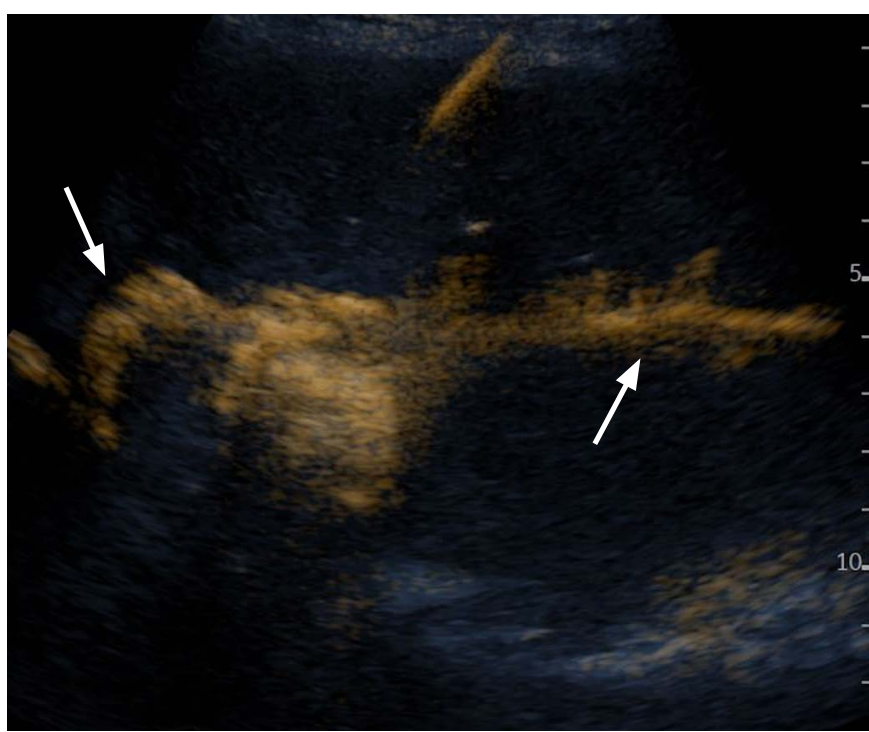

B

Fig. 7. Liver abscess.

A. Liver abscess after microwave ablation of a liver metastasis is shown. B. Contrast-enhanced ultrasonography reveals a communication between the drained liver abscess and large, segmental bile ducts (arrows). 
the map of drained regions through a quick scan of the entire liver parenchyma (Fig. 9), aid tube positioning, and/or detect prior aberrant lesions (bile leaks, fistulas, etc.), with similar results to those of fluoroscopy. Choosing between conventional fluoroscopy and CEUS cholangiography is, to this point, a matter of debate and, ultimately, a matter of personal preference. While image

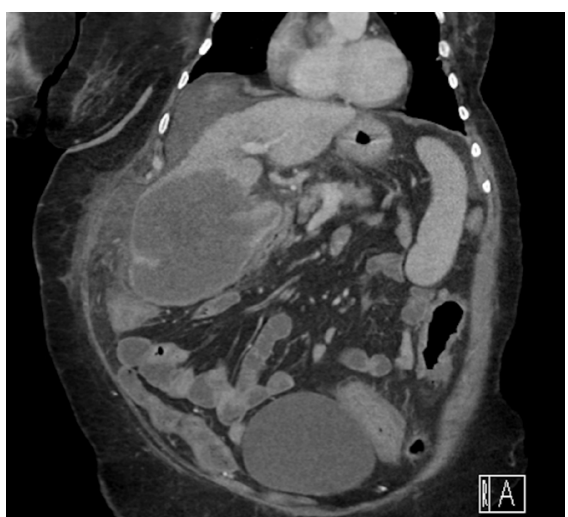

A

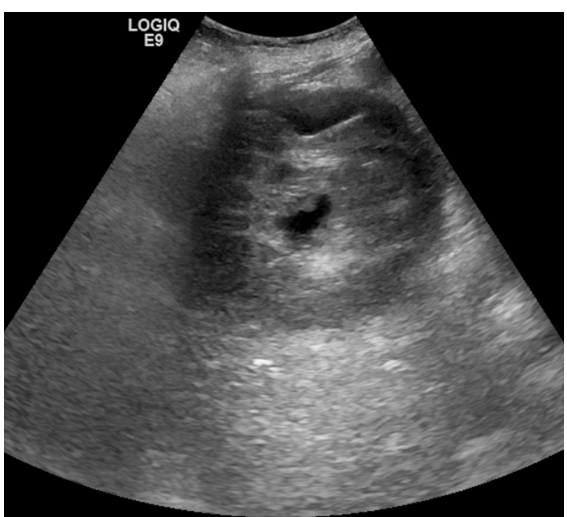

B

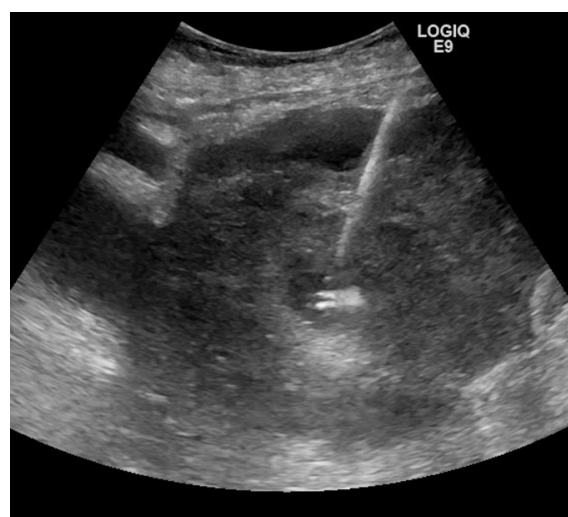

C

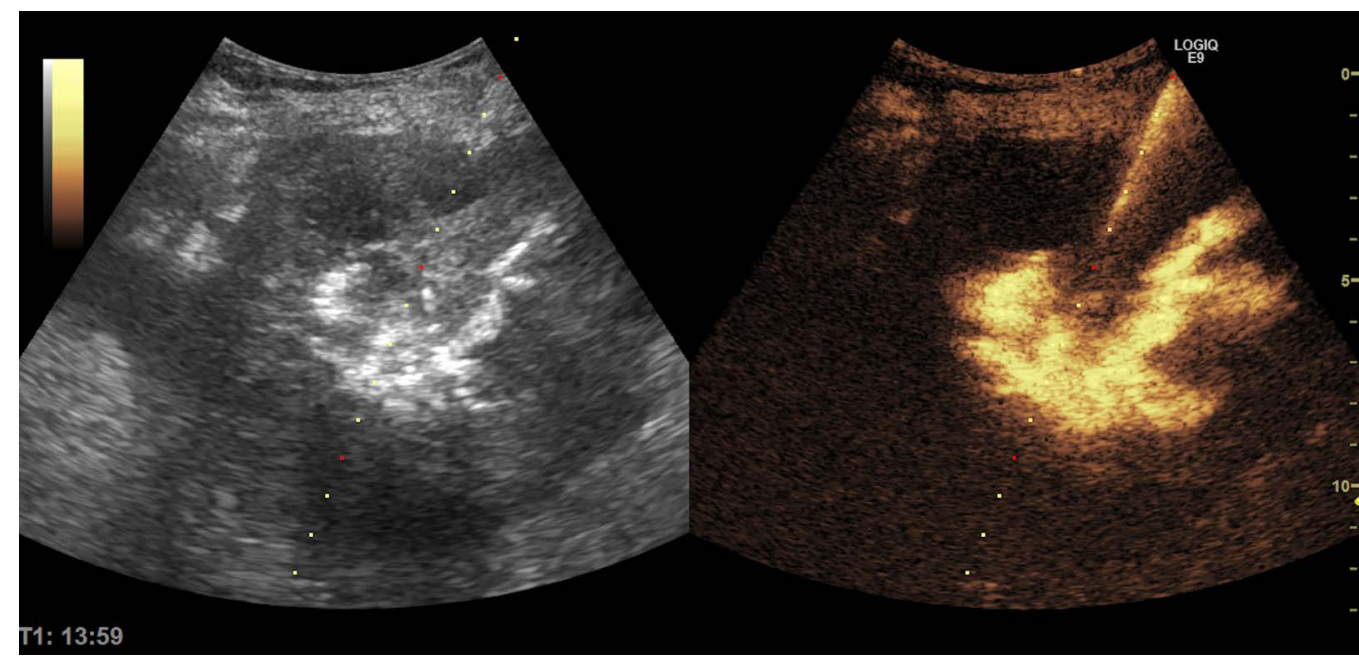

D

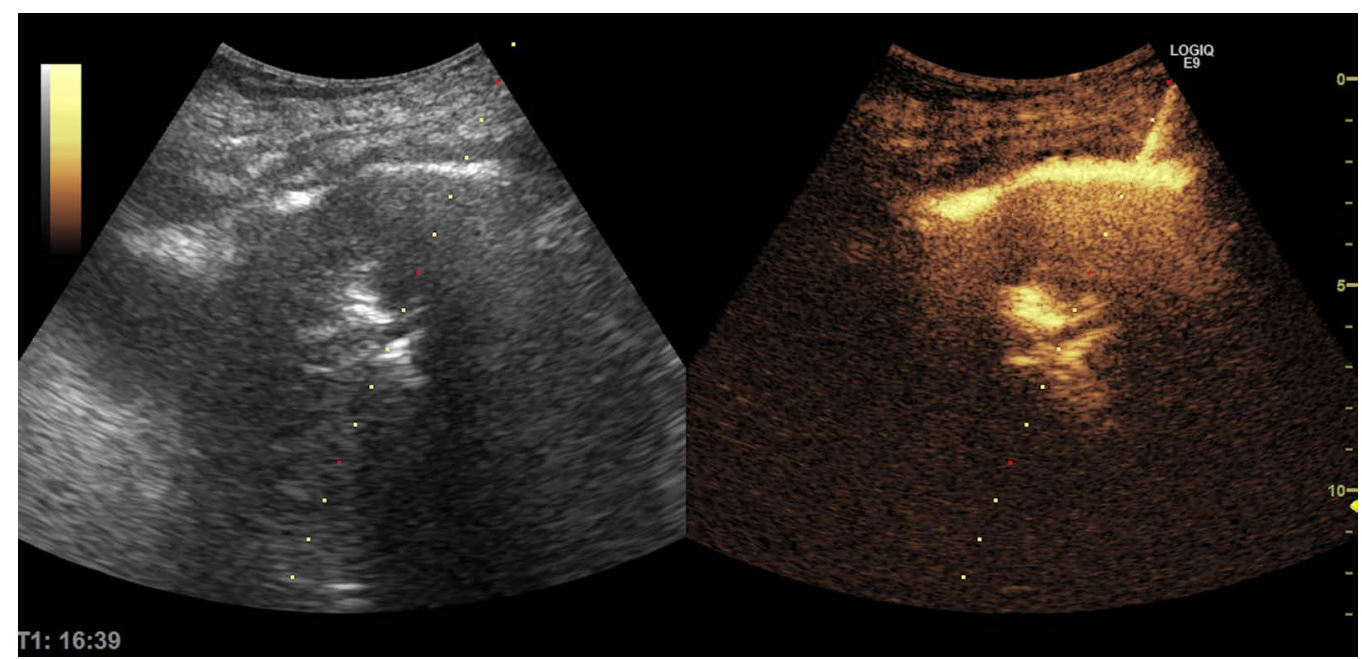

Fig. 8. A morbidly obese 55-year-old woman with high fever.

A. Computed tomography (CT) shows two fluid collections in relation to the liver, one centrally and one peripherally in the right lobe. B. Corresponding to the CT scan, ultrasonography (US) demonstrates similar findings with a $12-\mathrm{cm}$ complex mass containing both central and peripheral fluid collection. C-E. US-guided puncture with a $1.2-\mathrm{mm}$ lumbar needle performed so that the needle traversed both fluid collections (C), aspirated pus from both sites, and subsequent contrastenhanced ultrasonographic (CEUS) fistulography demonstrated no connection between the two cavities ( $D$, central abscess; E, peripheral abscess). Consequently, two separate 7-F loop-catheters were placed, one in each collection. This case clearly demonstrates the added value of CEUS fistulography.

E 
interpretation is not as straightforward and the spatial resolution might be lower, CEUS has the advantage of accessibility. The method can be performed in the US department, by the same operator who performed the drainage placement and can lead to a quick finetuning of the tube. There are no clear-cut data in favor of either of the two available methods $[6,39]$.

\section{Kidney: Pyelogram and Nephrostomy}

In kidney obstruction and drainage, CEUS plays a similar role as discussed in the biliary tree section. It provides a viable alternative to fluoroscopy, both in dilated and non-dilated pelvises, as well as in evaluating therapeutic success and stent patency [40-42]. Furthermore, it appears to be a valuable tool in evaluating the success rate of percutaneous nephrolithotomy [43]. Not least, prekidney puncture CEUS can delineate abnormal vascular patterns, thereby theoretically decreasing the complication rate.

\section{CEUS-Guided Tumor Ablation}

In the context of thermal ablation, CEUS falls into three categories: before, during, and after ablation [6]. The clinical benefits of using CEUS before ablation are as follows:

- Better delineation of the tumor size (in up to $56 \%$ of cases, the lesions were larger) and shape (in up to $49 \%$ of cases, the lesions were more irregular) [44]; this will translate into a higher complete necrosis rate and a lower complication rate when compared to B-mode US planning [44]

- Increasing the detection rate in patients with HCC (from 57\% to 96\%) [45]

- Revealing further ablation targets missed on conventional US

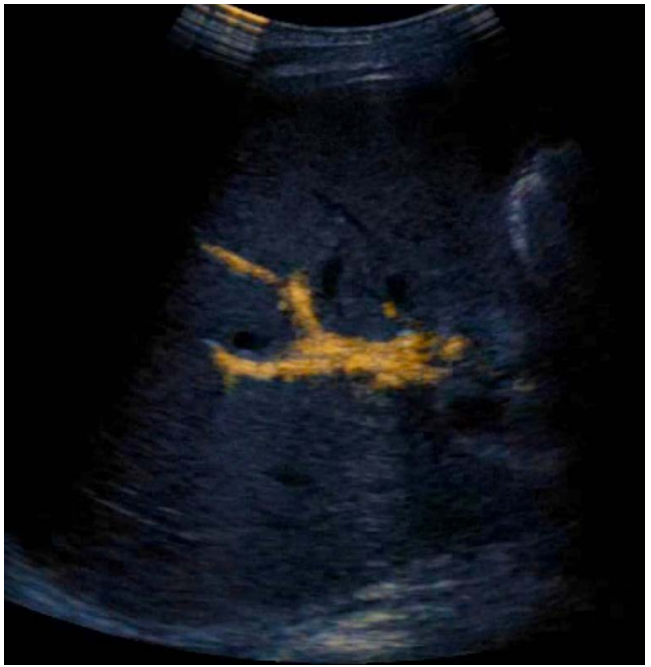

A

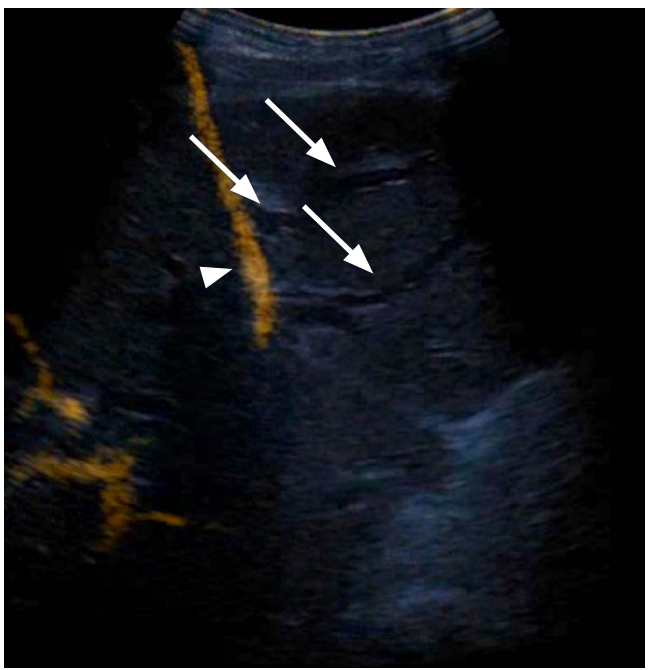

C

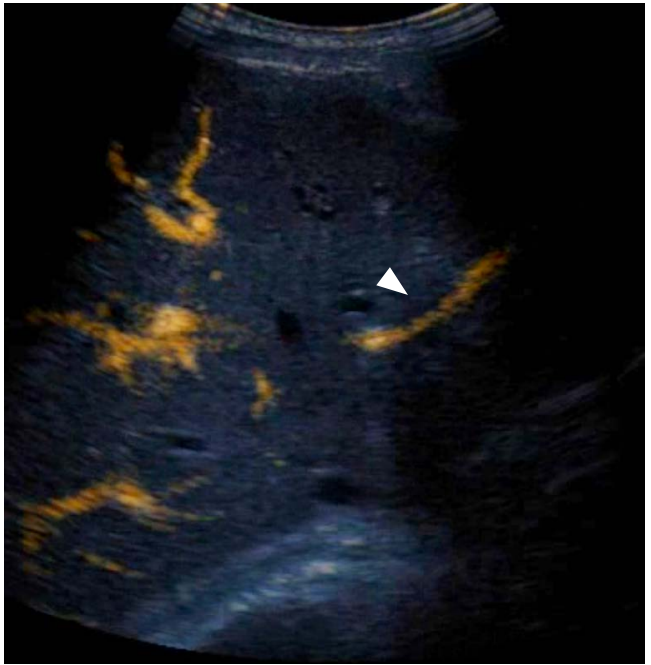

B

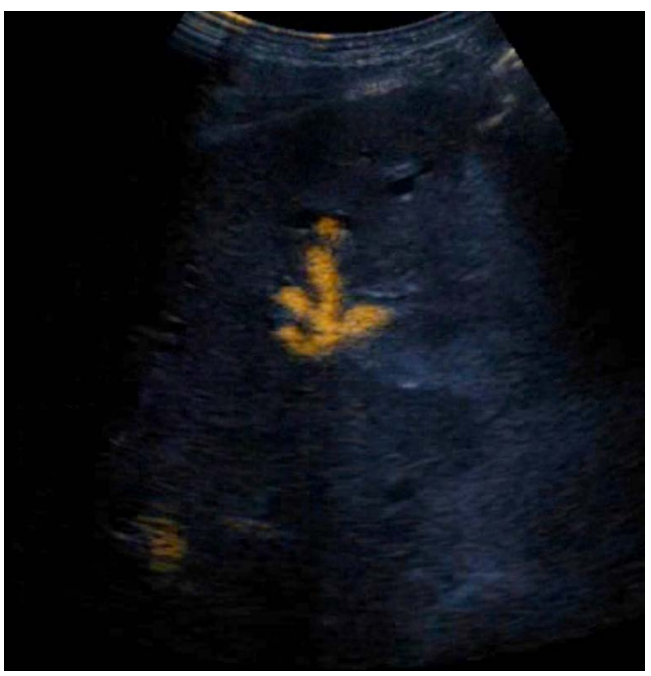

D
Fig. 9. Biliary obstruction.

An external biliary drainage catheter, initially placed in the common bile duct, was misplaced. Intracavitary contrast-enhanced ultrasonography (iCEUS) reveals that the catheter (arrowhead) adequately drained the right liver lobe, as the contrast agent was clearly visible in the biliary branches $(A, B)$. However, there was no contrast agent in the left liver lobe, as the dilated biliary branches were visible, but not enhanced (arrows, C) (arrowhead, catheter). Under iCEUS guidance, the tube was repositioned to expand the drainage to the left liver lobe. Consequently, large, previously undrained bile ducts were enhanced by the contrast agent (D). 


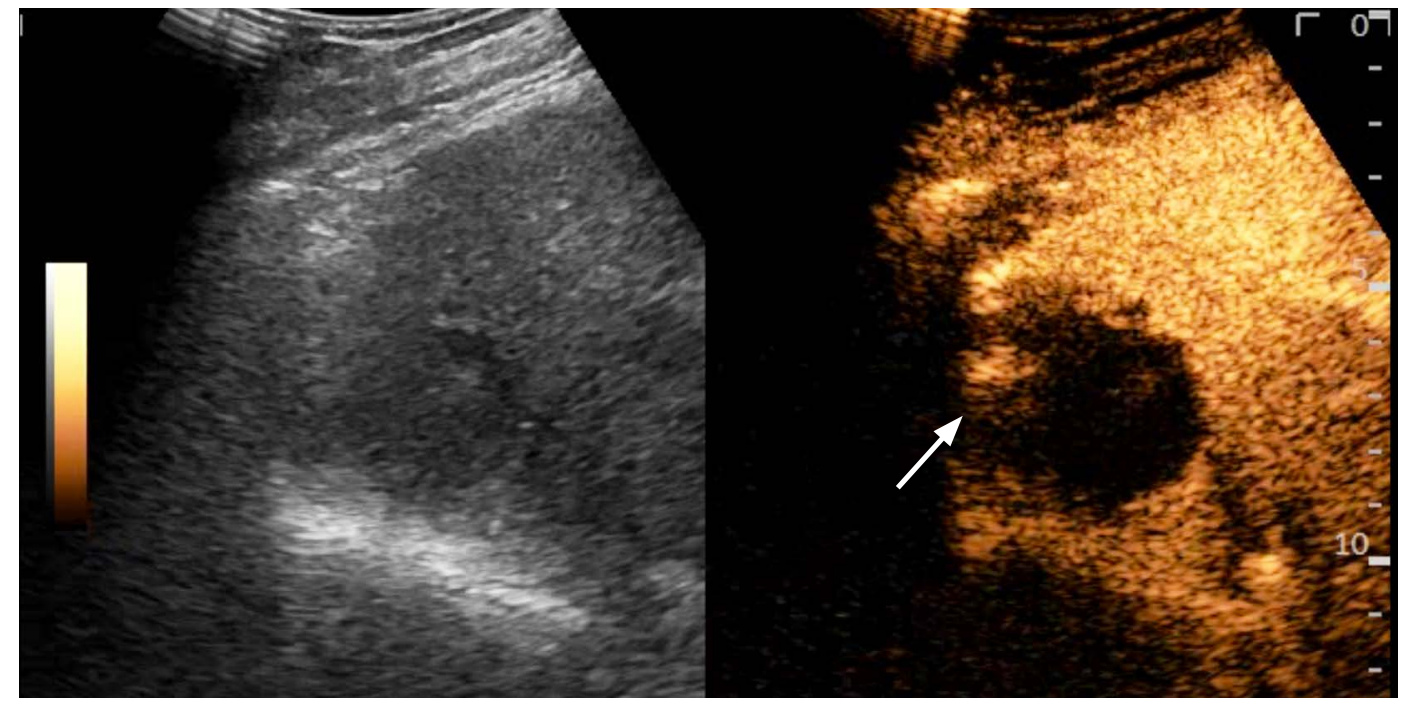

A

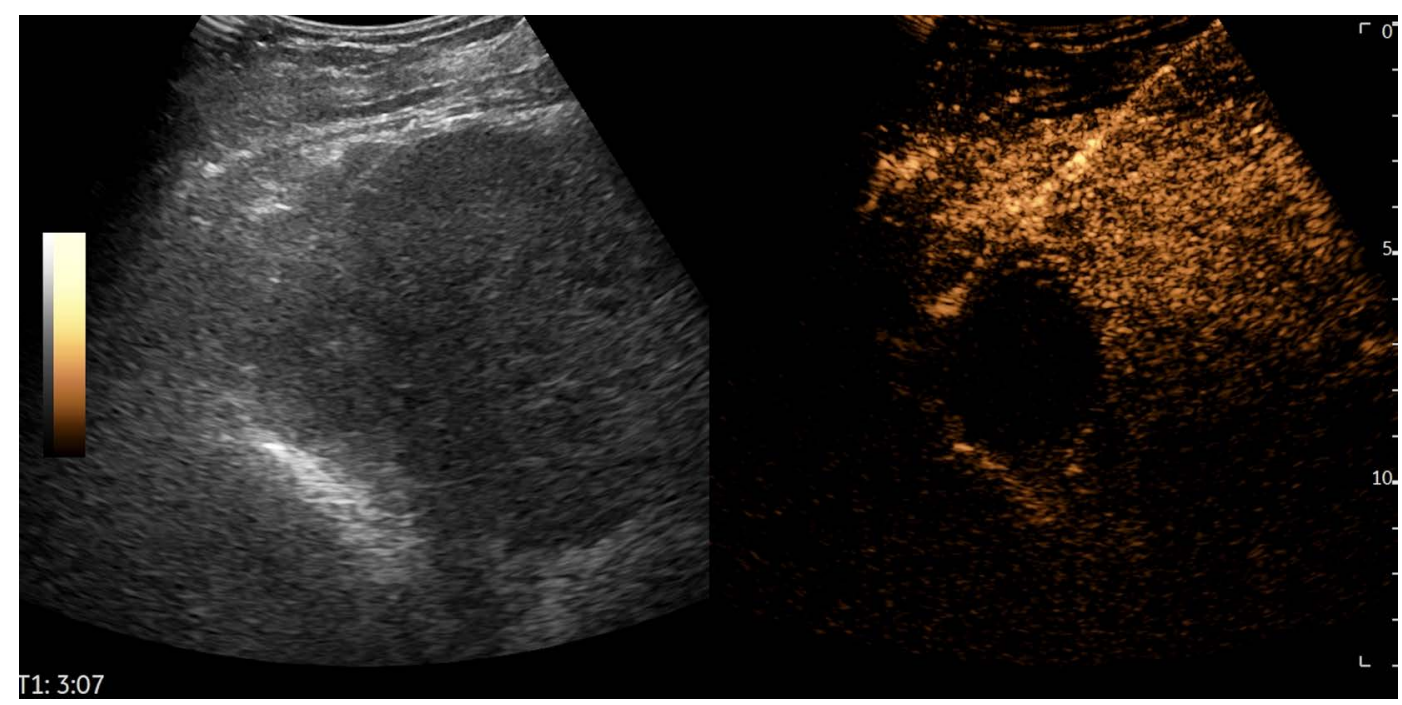

B

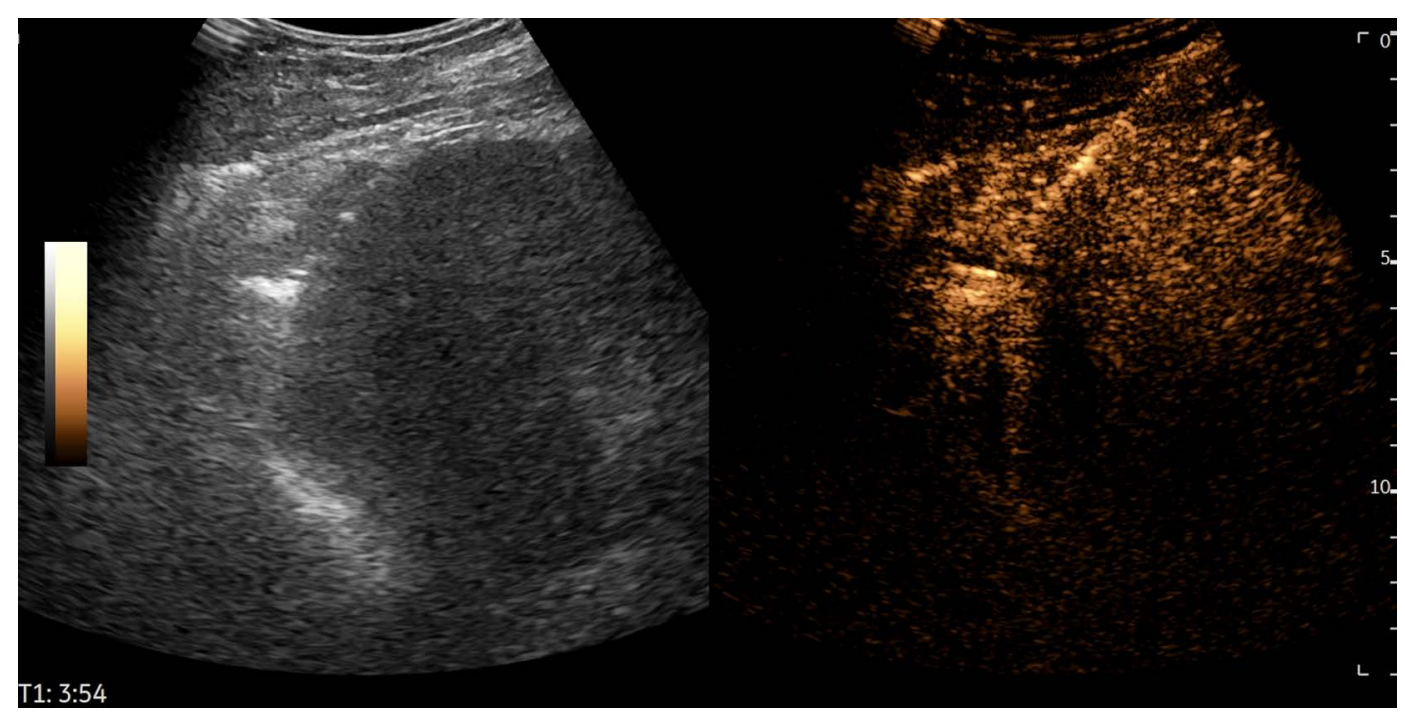

Fig. 10. Hepatocellular carcinoma previously treated using trans-arterial chemoembolization.

In a case of a previously treated hepatocellular carcinoma, contrast enhancement in ultrasonography reveals a hyperenhancing region within the necrotic area ( $A$, arrow). The microwave ablation electrode was guided in the hyperenhancing area during the arterial phase (B), and ablation was subsequently commenced (C). 
examinations in up to $13 \%$ of cases with liver metastases [46]

- In $75 \%$ to $98 \%$ of cases, CEUS was reported to visualize and guide ablation of HCC that was previously invisible or inconspicuous on conventional US imaging [6].

In the second setting, several studies have reported the technical success rate for CEUS-guided percutaneous thermal ablation. The clinical scenarios for which CEUS guidance is useful during ablation are target lesions detected on contrast-enhanced $\mathrm{CT}$ or contrastenhanced MRI and not visible on US, improvement of conspicuity of the target lesion, and depiction of a viable area inside nodules with either incomplete ablation after previous treatment or local tumor progression $[2,47]$.

CEUS performed during ablation is challenging, especially in

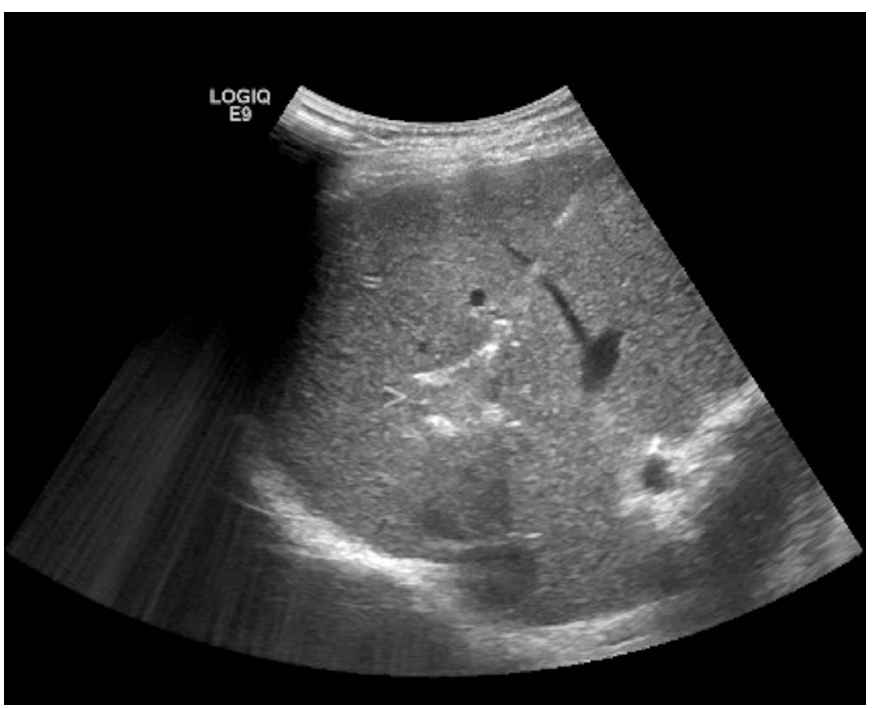

A

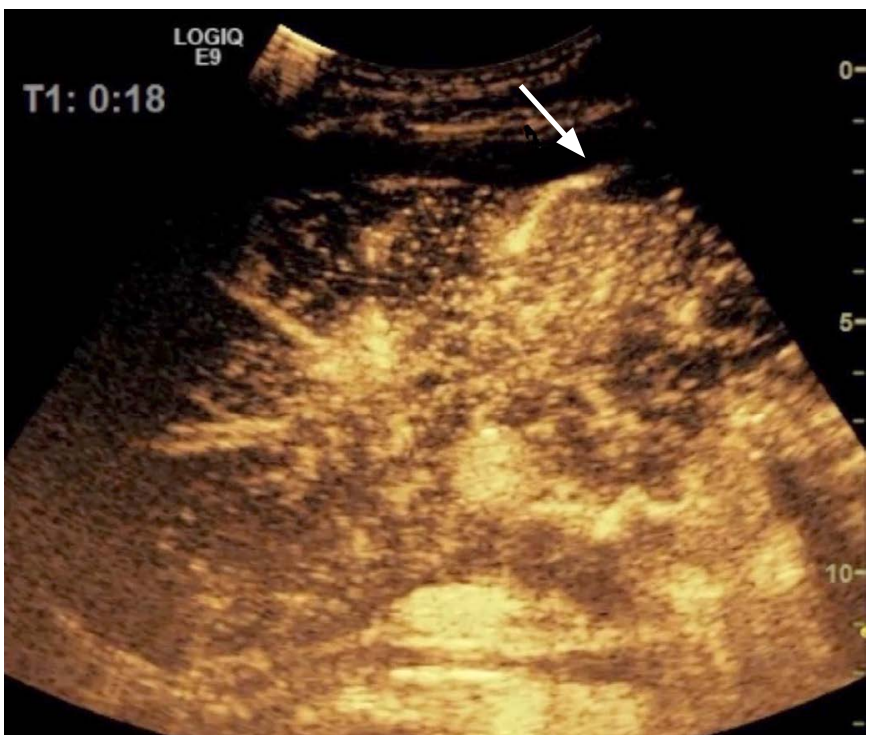

C

Fig. 11. Bleeding following the radiofrequency ablation of an 18$\mathrm{mm}$ metastasis in segment VII.

A. The radiofrequency ablation antenna was deployed in the nodule. B. Two-hour post-ablation, a perihepatic echogenic collection surrounding the liver was visualized at follow-up. C. Contrastenhanced ultrasonography in the arterial phase (18 seconds after contrast injection) reveals an active area of arterial bleeding (arrow). The patient was rushed to the operating room and the findings were confirmed intraoperatively.

patients with $\mathrm{HCC}$ (the contrast medium rapidly washes out of the liver in the arterial phase, the quality of the image is insufficient, and the tip of the ablation needle has a poor echogenicity in CEUS mode). In this situation, we suggest the use of CEUS fusion with contrast-enhanced CT or MRI since it can depict invisible or inconspicuous nodules on the conventional US [48]. More importantly, the use of fusion techniques for inconspicuous lesions resulted in similar results as conventional US guidance for clearly (49)

Lastly, CEUS is also a valuable clinical tool after therapy (Fig. 10), incomplete ablations and allow retreatment within the same session in up to $50 \%$ of cases [50]. This feature is of particular importance

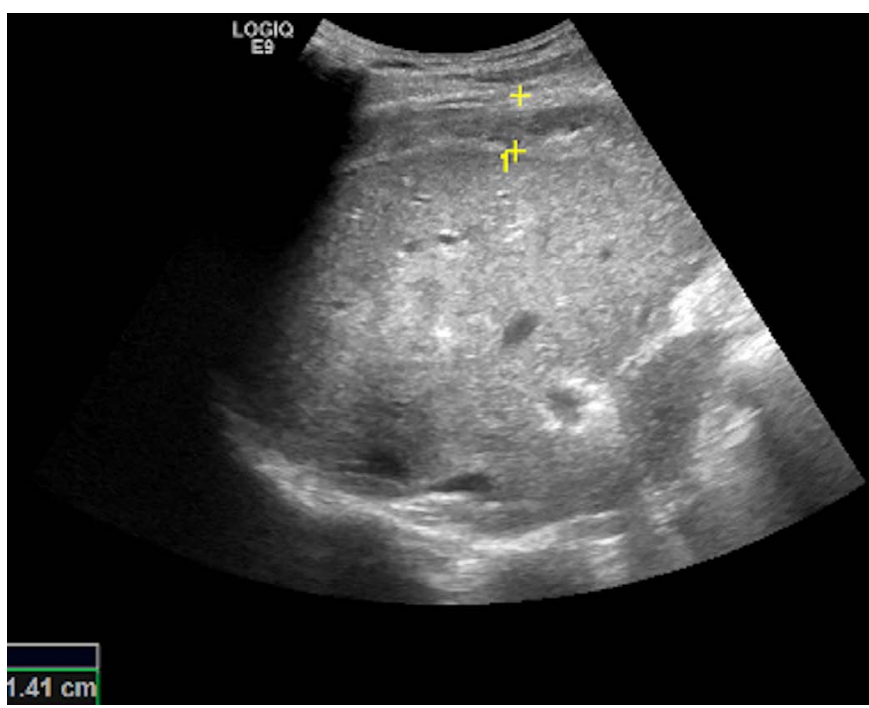

B 
Table 2. The CEUS appearances of various hemorrhagic vascular complications after

\begin{tabular}{|c|c|c|}
\hline Author & Type of complication & CEUS appearance \\
\hline $\begin{array}{l}\text { Nolsøe et al. (2018) [6], } \\
\text { Sparchez et al. (2021) [52] }\end{array}$ & Active bleeding along the needle track & $\begin{array}{l}\text { Linear extravasation of microbubbles in the vascular phase into the peritoneal } \\
\text { cavities }\end{array}$ \\
\hline $\begin{array}{l}\text { Nolsøe et al. (2018) [6], } \\
\text { Francica et al. (2021) [53] }\end{array}$ & Hemoperitoneum & $\begin{array}{l}\text { Jet-like extravasation of the contrast agents from variable pathological entities } \\
\text { into the perihepatic peritoneal space }\end{array}$ \\
\hline $\begin{array}{l}\text { Nolsøe et al. (2018) [6], } \\
\text { Francica et al. (2021) [53] }\end{array}$ & Subcapsular hematomas & Unenhanced intraparenchymal areas with convex margins \\
\hline Francica et al. (2021) [53] & Haemobilia & $\begin{array}{l}\text { Contrast agent bubbles filling the gallbladder lumen at the end of thermal } \\
\text { ablation in case of still active or echogenic unenhanced material in the } \\
\text { gallbladder lumen in case haemobilia stopped spontaneously }\end{array}$ \\
\hline Francica et al. (2021) [53] & Hemothorax & Extravasation of the contrast agents inside the pleural cavity \\
\hline
\end{tabular}

CEUS, contrast-enhanced ultrasonography.

since the residual tumor rate preferably should be as low as $0 \%$ [51]. On the other hand, when used as a follow-up evaluation tool, CEUS provides similar accuracy as CT or MRI for individual ablation targets.

\section{CEUS in the Detection of Hemorrhagic Vascular Complications in Interventional Procedures}

Albeit rare, some hemorrhagic vascular complications during or after US-guided interventions have been described. CEUS is an excellent tool for immediate detection and subsequent treatment planning (Fig. 11). The CEUS appearances of various hemorrhagic vascular complications after tumor ablation are depicted in Table 2.

\section{Conclusion}

The addition of CEUS to the interventional US armamentarium can offer substantial benefits ranging from preprocedural planning to real-time guidance and follow-up. There are numerous applications of contrast enhancement in clinical practice, from assisting biopsies, drainage procedures, and ablations, to post-procedural followup and detecting complications. The decision to use CEUS, as well as the timing and route of UCA delivery, makes a valuable contribution to the precision of the procedure. As the realm of USguided interventional procedures is ever-expanding, the judicious use of CEUS can provide a critical extra step in ensuring therapeutic success.

ORCID: Zeno Sparchez: https://orcid.org/0000-0002-3813-1677; Tudor Mocan: https://orcid.org/0000-0001-7785-6403; Rares Craciun: https://orcid.org/0000-00025872-8630; Mihaela Sparchez: https://orcid.org/0000-0001-8620-9160; Christian Nolsøe: https://orcid.org/0000-0003-0168-6131

\section{Author Contributions}

Conceptualization: Sparchez Z, Mocan T, Craciun R, Nolsøe C. Data acquisition: Sparchez Z, Craciun R, Nolsøe C. Data analysis or interpretation: Sparchez Z, Mocan T, Craciun R, Sparchez M. Drafting of the manuscript: Sparchez Z, Mocan T, Craciun R, Nolsøe C. Critical revision of the manuscript: Sparchez Z, Mocan T, Craciun R, Sparchez $M$, Nolsøe C. Approval of the final version of the manuscript: all authors.

\section{Conflict of Interest}

No potential conflict of interest relevant to this article was reported.

\section{References}

1. Nolsoe CP, Lorentzen T, Skjoldbye BO, Bachmann Nielsen M. The basics of interventional ultrasound. Ultraschall Med 2007;28:248263.

2. Lorentzen T, Nolsoe CP, Ewertsen C, Nielsen MB, Leen E, Havre RF, et al. EFSUMB guidelines on interventional ultrasound (INVUS), part I. General aspects (short version). Ultraschall Med 2015;36:464472.

3. Sidhu PS, Brabrand K, Cantisani V, Correas JM, Cui XW, D'Onofrio $M$, et al. EFSUMB guidelines on interventional ultrasound (INVUS), part II. Diagnostic ultrasound-guided interventional procedures (long version). Ultraschall Med 2015;36:E15-E35.

4. Dietrich CF, Lorentzen T, Appelbaum L, Buscarini E, Cantisani V, Correas JM, et al. EFSUMB guidelines on interventional ultrasound (INVUS), Part III. Abdominal treatment procedures (long version). Ultraschall Med 2016;37:E1-E32.

5. Kessner R, Nakamoto DA, Kondray V, Partovi S, Ahmed Y, Azar N. Contrast-enhanced ultrasound guidance for interventional procedures. J Ultrasound Med 2019;38:2541-2557.

6. Nolsoe CP, Nolsoe AB, Klubien J, Pommergaard HC, Rosenberg J, Meloni $\mathrm{MF}$, et al. Use of ultrasound contrast agents in relation to percutaneous interventional procedures: a systematic review and 
pictorial essay. J Ultrasound Med 2018;37:1305-1324.

7. Dietrich CF, Nolsoe CP, Barr RG, Berzigotti A, Burns PN, Cantisani $\mathrm{V}$, et al. Guidelines and good clinical practice recommendations for contrast enhanced ultrasound (CEUS) in the liver - update 2020 WFUMB in cooperation with EFSUMB, AFSUMB, AIUM, and FLAUS. Ultraschall Med 2020;41:562-585.

8. Nolsoe CP, Lorentzen T. International guidelines for contrastenhanced ultrasonography: ultrasound imaging in the new millennium. Ultrasonography 2016;35:89-103.

9. Huang DY, Yusuf GT, Daneshi M, Ramnarine R, Deganello A, Sellars $M E$, et al. Contrast-enhanced ultrasound (CEUS) in abdominal intervention. Abdom Radiol (NY) 2018;43:960-976.

10. Strobel D, Seitz K, Blank W, Schuler A, Dietrich C, von Herbay A, et al. Contrast-enhanced ultrasound for the characterization of focal liver lesions: diagnostic accuracy in clinical practice (DEGUM multicenter trial). Ultraschall Med 2008;29:499-505.

11. Huang DY, Yusuf GT, Daneshi M, Husainy MA, Ramnarine R, Sellars $M E$, et al. Contrast-enhanced US-guided interventions: improving success rate and avoiding complications using US contrast agents. Radiographics 2017;37:652-664.

12. Marschner CA, Rubenthaler J, Froelich MF, Schwarze V, Clevert DA. Benefits of contrast-enhanced ultrasonography for interventional procedures. Ultrasonography 2021;40:207-216.

13. Sparchez Z, Radu P, Zaharia T, Kacso G, Grigorescu I, Badea R. Contrast enhanced ultrasound guidance: a new tool to improve accuracy in percutaneous biopsies. Med Ultrason 2010;12:133138.

14. Muller T, Blank W, Leitlein J, Kubicka S, Heinzmann A. Endocavitary contrast-enhanced ultrasound: a technique whose time has come? J Clin Ultrasound 2015;43:71-80.

15. Sparchez Z, Radu P, Sparchez M, Vasile T, Anton O, Tantau M. Intracavitary applications of ultrasound contrast agents in hepatogastroenterology. J Gastrointestin Liver Dis 2013;22:349353.

16. Wu W, Chen MH, Yin SS, Yan K, Fan ZH, Yang W, et al. The role of contrast-enhanced sonography of focal liver lesions before percutaneous biopsy. AJR Am J Roentgenol 2006;187:752-761.

17. Skjoldbye B, Pedersen MH, Struckmann J, Burcharth F, Larsen T. Improved detection and biopsy of solid liver lesions using pulseinversion ultrasound scanning and contrast agent infusion. Ultrasound Med Biol 2002;28:439-444.

18. Schlottmann K, Klebl F, Zorger N, Feuerbach S, Scholmerich J. Contrast-enhanced ultrasound allows for interventions of hepatic lesions which are invisible on convential B-mode. Z Gastroenterol 2004;42:303-310.

19. Yoon SH, Lee KH, Kim SY, Kim YH, Kim JH, Lee SH, et al. Realtime contrast-enhanced ultrasound-guided biopsy of focal hepatic lesions not localised on B-mode ultrasound. Eur Radiol 2010;20:2047-2056.
20. Cao X, Liu Z, Zhou X, Geng C, Chang Q, Zhu L, et al. Usefulness of real-time contrast-enhanced ultrasound guided coaxial needle biopsy for focal liver lesions. Abdom Radiol (NY) 2019;44:310-317.

21. Kessner R, Partovi S, Nakamoto D, Lu Z, Yu A, Patel IJ, et al. Contrast-enhanced ultrasound for guidance of percutaneous liver interventions in neoplastic hepatic disease. Dig Dis Interv 2017; 1:201-207.

22. Lim S, Lee MW, Rhim H, Cha DI, Kang TW, Min JH, et al. Mistargeting after fusion imaging-guided percutaneous radiofrequency ablation of hepatocellular carcinomas. J Vasc Interv Radiol 2014;25:307-314.

23. Minami Y, Kudo M. Image guidance in ablation for hepatocellular carcinoma: contrast-enhanced ultrasound and fusion imaging. Front Oncol 2021;11:593636.

24. Di Vece F, Tombesi P, Ermili F, Sartori S. Contrast-enhanced ultrasound (CEUS) and CEUS-guided biopsy in the diagnosis of lung abscess in a patient with achalasia: Case report. Interv Med Appl Sci 2013;5:31-33.

25. Lei Z, Lou J, Bao L, Lv Z. Contrast-enhanced ultrasound for needle biopsy of central lung cancer with atelectasis. J Med Ultrason (2001) 2018;45:461-467.

26. Sparchez Z, Mocan T, Hagiu C, Kacso G, Zaharie T, Rusu I, et al. Real-time contrast-enhanced-guided biopsy compared with conventional ultrasound-guided biopsy in the diagnosis of hepatic tumors on a background of advanced chronic liver disease: a prospective, randomized, clinical trial. Ultrasound Med Biol 2019;45:2915-2924.

27. Lorentzen T, Nolsoe CP. The role of US contrast agents in US-guided biopsy of focal liver lesions: a pictorial review. Ultrasound Int Open 2019;5:E11-E19.

28. Sparchez Z, Radu P, Zaharia T, Kacso G, Grigorescu I, Botis G, et al. Usefulness of contrast enhanced ultrasound guidance in percutaneous biopsies of liver tumors. J Gastrointestin Liver Dis 2011;20:191-196.

29. Liang J, Wang D, Li H, Zhao S, Chen M, Li H, et al. Contrastenhanced ultrasound for needle biopsy of thoracic lesions. Oncol Lett 2020;20:75.

30. Sparchez Z, Radu P, Kacso G, Sparchez M, Zaharia T, Al Hajjar N. Prospective comparison between real time contrast enhanced and conventional ultrasound guidance in percutaneous biopsies of liver tumors. Med Ultrason 2015;17:456-463.

31. Eso Y, Takai A, Takeda H, Matsumoto T, Lee M, Inuzuka T, et al. Sonazoid-enhanced ultrasonography guidance improves the quality of pathological diagnosis in the biopsy of focal hepatic lesions. Eur J Gastroenterol Hepatol 2016;28:1462-1467.

32. Kang TW, Lee MW, Song KD, Kim M, Kim SS, Kim SH, et al. Added value of contrast-enhanced ultrasound on biopsies of focal hepatic lesions invisible on fusion imaging guidance. Korean J Radiol 2017;18:152-161. 
33. Kang HJ, Kim JH, Lee SM, Yang HK, Ahn SJ, Han JK. Additional value of contrast-enhanced ultrasonography for fusion-guided, percutaneous biopsies of focal liver lesions: prospective feasibility study. Abdom Radiol (NY) 2018;43:3279-3287.

34. Sparchez Z, Radu P, Kacso G, Eniu DT, Hica S, Sparchez M. Performance of CEUS guided biopsy in large renal and adrenal tumors. Ultrasound Med Biol 2011;37(Suppl):S33.

35. Sparchez Z, Radu P, Al Hajjar N, Kacso G, Mocan T. Prospective comparison US vs. CEUS guided percutaneous biopsy in the diagnosis of large intra-and retroperitoneal tumors. Insight Imaging 2018;9(Suppl 1):S284.

36. Francica G, Meloni MF, de Sio I, Terracciano F, Caturelli E, Riccardi $L$, et al. Biopsy of liver target lesions under contrast-enhanced ultrasound guidance: a multi-center study. Ultraschall Med 2018;39:448-453.

37. Morita M, Ogawa C, Omura A, Noda T, Kubo A, Matsunaka T, et al. The efficacy of sonazoid-enhanced ultrasonography in decisionmaking for liver abscess treatment. Intern Med 2020;59:471-477.

38. Ignee A, Jenssen C, Cui XW, Schuessler G, Dietrich CF. Intracavitary contrast-enhanced ultrasound in abscess drainage: feasibility and clinical value. Scand J Gastroenterol 2016;51:41-47.

39. Ignee A, Cui X, Schuessler G, Dietrich CF. Percutaneous transhepatic cholangiography and drainage using extravascular contrast enhanced ultrasound. Z Gastroenterol 2015;53:385-390.

40. Cui XW, Ignee A, Maros T, Straub B, Wen JG, Dietrich CF. Feasibility and usefulness of intra-cavitary contrast-enhanced ultrasound in percutaneous nephrostomy. Ultrasound Med Biol 2016;42:21802188.

41. Liu BX, Huang GL, Xie XH, Zhuang BW, Xie XY, Lu MD. Contrastenhanced US-assisted percutaneous nephrostomy: a technique to increase success rate for patients with nondilated renal collecting system. Radiology 2017;285:293-301.

42. Daneshi M, Yusuf GT, Fang C, Sellars ME, Huang DY, Sidhu PS. Contrast-enhanced ultrasound (CEUS) nephrostogram: utility and accuracy as an alternative to fluoroscopic imaging of the urinary tract. Clin Radiol 2019;74:167.

43. Fetzer DT, Flanagan J, Nabhan A, Pongsatianwong K, Antonelli J, Pearle $\mathrm{M}$, et al. Impact of implementing contrast-enhanced ultrasound for antegrade nephrostogram after percutaneous nephrolithotomy. J Ultrasound Med 2021;40:101-111.
44. Chen MH, Yang W, Yan K, Dai Y, Wu W, Fan ZH, et al. The role of contrast-enhanced ultrasound in planning treatment protocols for hepatocellular carcinoma before radiofrequency ablation. Clin Radiol 2007;62:752-760.

45. Miyamoto N, Hiramatsu K, Tsuchiya K, Sato Y, Terae S, Shirato H. Sonazoid-enhanced sonography for guiding radiofrequency ablation for hepatocellular carcinoma: better tumor visualization by Kupfferphase imaging and vascular-phase imaging after reinjection. Jpn J Radiol 2009;27:185-193.

46. Meloni MF, Livraghi T, Filice C, Lazzaroni S, Calliada F, Perretti L. Radiofrequency ablation of liver tumors: the role of microbubble ultrasound contrast agents. Ultrasound Q 2006;22:41-47.

47. Francica G, Meloni MF, Riccardi L, de Sio I, Terracciano F, Caturelli $E$, et al. Ablation treatment of primary and secondary liver tumors under contrast-enhanced ultrasound guidance in field practice of interventional ultrasound centers: a multicenter study. Eur J Radiol 2018;105:96-101.

48. Bo $X W$, Xu HX, Wang $D$, Guo LH, Sun $L P$, Li XL, et al. Fusion imaging of contrast-enhanced ultrasound and contrast-enhanced $C T$ or MRI before radiofrequency ablation for liver cancers. $\mathrm{Br} J$ Radiol 2016;89:20160379.

49. Calandri M, Mauri G, Yevich S, Gazzera C, Basile D, Gatti M, et al. Fusion imaging and virtual navigation to guide percutaneous thermal ablation of hepatocellular carcinoma: a review of the literature. Cardiovasc Intervent Radiol 2019;42:639-647.

50. Wiggermann P, Zuber-Jerger I, Zausig Y, Loss M, Scherer MN, Schreyer $A G$, et al. Contrast-enhanced ultrasound improves realtime imaging of ablation region during radiofrequency ablation: preliminary results. Clin Hemorheol Microcirc 2011;49:43-54.

51. Lekht I, Gulati M, Nayyar M, Katz MD, Ter-Oganesyan R, Marx M, et al. Role of contrast-enhanced ultrasound (CEUS) in evaluation of thermal ablation zone. Abdom Radiol (NY) 2016;41:1511-1521.

52. Sparchez Z, Mocan T, Matei D, Popa O, Al Hajjar N. Bleeding after microwave ablation in hepatocellular carcinoma: successful treatment with percutaneous ultrasound-guided cyanoacrylate glue embolization. Ultraschall Med 2021;42:202-203.

53. Francica G, Meloni MF, Riccardi L, Giangregorio F, Caturelli E, Terracciano $F$, et al. Role of contrast-enhanced ultrasound in the detection of complications after ultrasound-guided liver interventional procedures. J Ultrasound Med 2021;40:1665-1673. 